\title{
COURNOT COMPETITION UNDER KNIGHTIAN UNCERTAINTY
}

\author{
Hugo Pedro Boff*
}

Sergio Ribeiro da Costa Werlang**

\begin{abstract}
This article applies a theorem of Nash equilibrium under uncertainty (Dow \& Werlang, 1994) to the classic Cournot model of oligopolistic competition. It shows, in particular, how one can map all Cournot-Nash equilibria (which includes the cartel and the null solutions) to only a function of the uncertainty aversion coefficients of the producers. The effects of these parameters on the symmetric equilibrium quantities and output are examined in a comparative statics analysis, under two alternative assumptions: a closed market with an exogenous number of firms and a free-entry/exit regime. In both cases, a collusive effect of the uncertainty aversion on the production is obtained. Under rather few restrictive assumptions, there is a symmetric uncertainty aversion level for the producers at which their optimal quantities and the industry output become equal to the optimal counterpart cartel's outcomes. These results improve upon the literature on collusion since, in contrast to other analogous findings, they enhance that a cooperative cartel may be endogenously generated in a one-shot (noncooperative) game played by uncertainty averse producers. For the competitive case (under free-entry/exit) the paper shows that Cournotian competition among weakely or moderately uncertainty averse producers entails a higher industry output (if the market is large and/or entry is easy) and surely entails lower optimal quantities for the firms than those achieved under uncertainty neutrality . Thus, competition under free-entry/exit in a Knightian uncertainty environment should act to prevent monopoly power for the individual firms.
\end{abstract}

"IE/UFRJ, Rio de Janeiro, Brazil. The author acknowledges financial assistance granted by CAPES/PICD - National Education Ministry.

**EPGE, Getulio Vargas Foundation and BACEN, Brazilian Central Bank, Brazil.

\begin{tabular}{llll}
\hline R. de Econometria Rio de Janeiro & v. 18, $\mathrm{n}^{2}$ 2, pp. 265-308 & Novembro 1998 \\
\hline
\end{tabular} 


\section{Cournot Competition under Knightian Uncertainty}

\section{Resumo}

Neste artigo aplica-se o conceito de equilíbrio de Nash sob incerteza (Dow \& Werlang, 1994) ao modelo clássico de Cournot para competição oligopolística. Este conceito é estendido para o caso de um número finito de jogadores. Em particular, mostra-se como todos os equilíbrios Cournot-Nash resultantes (que incluem as soluçōes de cartel e o bloqueio da produção) podem ser mapeados em função, unicamente, dos coeficientes de aversão à incerteza dos produtores. A estática comparativa dos efeitos destes parâmetros sobre a produção das firmas e da indústria é realizada sob dois regimes: o de uma indústria fechada com um número de firmas endogenamente determinado. Em ambos os casos, os efeitos colusivos da aversão à incerteza são explicitados. Sob hipóteses pouco restritivas mostra-se, em cada caso, que existe um coeficiente de aversão à incerteza simétrico que iguala o produto industrial com aquele que maximiza o lucro da coalisão formada pelos mesmos produtores. Tais resultados implementam a literatura existente sobre a performance das coalisōes pois que, diferentemente dos resultados anteriores, evidenciam como o resultado ótimo de um cartel cooperativo pode ser endogenamente gerado por uma economia nāo-cooperativa protagonizada por decisores individualmente avessos-à-incerteza. Sob o regime de livre entrada/saída, a competição de Cournot entre produtores fracamente (ou moderadamente) avessos à incerteza abre a possibilidade para um aumento no produto industrial (e, consequentemente, no bem-estar gerado pela indústria), sempre que o mercado for suficientemente amplo e/ou a entrada das firmas no mercado for facilitada. Entretanto, a aversão-à-incerteza gera ociosidade crescente na escala de produção das firmas, com relação ao comportamento neutro face à incerteza. Deste modo, o artigo sublinha que o regime de livre entrada/saída em um ambiente de aversão à incerteza (no sentido de Knight), atua no sentido de obstar o poder de monopolização das firmas individuais. Uma aplicação ilustrativa destes e de outros resultados apresentados no trabalho é oferecida com os parâmetros de uma economia com demanda linear e tecnologia exibindo retornos de escala decrescentes na produção. Outras extensōes e aplicaçōes do presente modelo são também sugeridas.

Key words: Knightian uncertainty aversion, Cournot-Nash equilibrium.

JEL Code: C72, D43, D81. 


\section{Introduction.}

In the rational model of choice under Knightian uncertainty ${ }^{1}$ as proposed in Schmeidler (1989), agents evaluate the consequences of their actions by nonadditive probability functions defined on a given space (states of nature), and maximize their expected utility, using Choquet's integral. ${ }^{2}$ When the nonadditive distributions (say, $P$ ) are convex (i.e. exhibit uncertainty aversion) this model is equivalent to the maximin model (Schmeidler \& Gilboa, 1989) where the relevant distribution is built up as the infimum probability among every additive distribution belonging to the core of $P$, for each choice in the alternative set.

For every pairwise choice $A, B$ in the alternative set, convexity of $P$ requires $P(A)+P(B) \leq P(P \cap B)+P(A \cup B)$, which implies $P(A)+P\left(A^{c}\right) \leq 1\left(B=A^{c}\right)$. In Schmeidler and Gilboa axiomatic approach, the difference $c(P, A)=1-P(A)-P\left(A^{c}\right)$ is interpreted as an uncertainty aversion coefficient associated to event $A$, and more recently Dow \& Werlang (1994) extended to this framework the notion of Nash Equilibrium for a one-shot game with 2 agents. Under uniform squeezes of additive mixed strategies assumption (leading to constant uncertainty aversion coefficients), they demonstrate the existence of Nash equilibrium under uncertainty (NEU) for each pair $\left(c_{1}, c_{2}\right)$ of uncertainty aversion of players.

In this article, we first state the definition and then the existence theorem for NEU as it is presented in the Dow \& Werlang paper (Section 2). Section 3 initially presents the decision under uncertainty model enabling one to extend the definition of a NEU

\footnotetext{
${ }^{1}$ F.H. Knight(1921): Agents do not know the objective probability distribution finctions (pdf) of the states of the nature affecting the control variables they face and are unable to formulate a unique subjective pdf.

${ }^{2}$ For an exposition on nonadditive probabilities and the applications of this model in finance, see Simonsen \& Werlang (1991) and Dow \& Werlang (1992a,b).
} 
for a Cournot game with $N$ producers, when quantities (the control variable) are chosen over compact and convex sets. We will show, in a general case, how the equilibrium output that results responds to exogenous variations in the uncertainty aversion parameters (proposition 1 and corollary 1). Also, such reactions are examined when the number $N$ of competitors exogenously increase (Section 3.3). In the following subsection we made a theoretical identification of the producers uncertainty aversion parameters (which depend on their preferences' systems) with the price-cost Lerner index. In a comparative statics viewpoint, the paper main results are obtained under symmetric assumptions: firms are identical and producers equally uncertainty averse (Section 4). The effects of small variations of the aversion parameters on the industry output, on the frms's quantities and on the industry size (under free-entry/exit) could be signed in this case. Particularly, it shows that the uncertainty aversion exerts a depressive effect on industry output (and then, an inflationary effect on price) for closed industries only (Section 4.2). This result (incidentally also confirmed in risk aversion approaches) no longer holds when producers are allowed to enter or to exit from the industry (Section 4.3). In this case, the industry output with weakly or moderately uncertainty averse producers could be higher than its counterpart under uncertainty neutrality, whenever the market is large and/or the entry conditions into the industry are easy (in terms of the fixed costs and the elasticity parameters). The comparative statics for the competitive industry also shows that the optimal firms' quantities are lower in almost all admissible ranges for the uncertainty aversion parameter. In contrast with the ambiguous findings met in analysis of the industry equilibrium from a risk framework (Appelbaum \& Katz,1986) our result suggests that, at the equilibrium under uncertainty aversion, firms operate with "undercapacity". Also, our paper sets up an innovative application from a game theoretical point-of-view, since it enables us to show how 
a cooperative (cartel) outcome may be endogenously generated in a one-shot game played by self-seeking and uncertainty averse players. Without uncertainty, such a result is only obtained in sequential or repeated games, with exogenous coalitional structures. Proposition 2 establishes our result for an exogenous number of players whereas proposition 3 sets the equivalent result for an open industry by using the fact that, for each symmetric uncertainty aversion parameter $c$ (in the admissible range) there is a theoretical symmetric game for $\left[N_{\omega}(c)\right]$ players where Nash optimal strategies under uncertainty give zero payoff for all them. The analysis of the effects of the uncertainty aversion on the market structure under free-entry/exit shows a decreasing market share for the firms $\left(r_{\omega}(c)=1 /\left[N_{\omega}(c)\right]\right)$ up to the collusive uncertainty level $\widehat{c}_{\omega}$. Thus, another finding of our model states that Cournotian competition among uncertainty averse producers inside an open industry may endogenously prevent the monopoly power of the individual firms. Neverthless, this result hinges strongly on symmetric assumptions and the example given in the last section (Section 5$)$ for a duopoly $(N=2)$ enhances explicitly the role of the asymmetries in which Cournotian equilibria under uncertainty will emerge. The last section makes also mention of possible extensions of the present analysis and summarizes the principal findings of the paper. The present results offer interesting suggestions for market regulatory policies aimed to preserve a reasonable degree of competitiveness among the firms in order to protect consumers from overpricing due to market power (like the Clayton Act in USA). In the first place, even for noncompetitive (closed) industries the collusive effects obtained here tell that the current anti-trust laws based on the market share profile of the industry may be powerless to protect the consumers from monopolistic conduct. Secondly, differences in the results obtained for competitive industries stress the importance of implementing actions directed to guarantee that the proponent firms meet easy conditions to enter the market. 


\section{Nash Equilibrium under Uncertainty (NEU).}

Let $\Gamma:\left(A_{1}, A_{2}, u_{1}, u_{2}\right)$ a 2-person game where $A_{1}$ and $A_{2}$ are their alternative sets and $u_{1}, u_{2}$, their utility functions. A NEU for the game $\Gamma$ is defined by a pair of mixed nonadditive strategies $\left(R_{1}, R_{2}\right)$ for which there exist supports Supp $\left(R_{1}\right)$, Supp $\left(R_{2}\right)^{3}$ such that for each $a_{i} \in \operatorname{supp}\left(R_{i}\right), a_{i}$ maximizes the expected utility of player $i$, given that $R_{j}$ represents the conjecture of player $i$ about the choices of player $j$ over $A_{j}$ :

$$
a_{i} \in \operatorname{supp}\left(R_{i}\right) \Longleftrightarrow a_{i} \in \underset{a \in A_{i}}{\arg \max } E_{R_{j}} u_{i}(a, \cdot) \quad(i, j=1,2) .
$$

Notice that this definition includes the standard Nash equilibrium $\left(S_{1}, S_{2}\right)$, where $\left(S_{1}, S_{2}\right)$ are some proper additive probability functions. In the application of the above definition we have to keep in mind two important aspects, which were both emphasized by Dow \& Werlang in their paper (p. 307):

1. All action in the support of the conjecture of a player $j$ must be optimal for player $i$ when he assess his utility w.r.t. his own conjecture on the actions of his opponent $j$. So, NEU requires a perfect match between conjectures and optimal actions taken by players;

2. The rationality which is implicit in the NEU definition does not imply logical omniscience, meaning that agents may not rightly deduct all implications of some action previously known by them.

The following theorem allows one to map NEU's through the uncertainty aversion coefficients $\left(c_{1}, c_{2}\right)$ of players, under the hypothesis

\footnotetext{
${ }^{3}$ Define $R_{j}: \sigma\left(A_{j}\right) \rightarrow[0,1]$ the nonadditive probability function (a capacity) giving the probability $R_{j}(B)$ for each event $B \in \sigma\left(A_{j}\right)$, where $\sigma\left(A_{j}\right)$ is the $\sigma$-algebra of subsets of $A_{j}$. The finction $R_{j}$ has the following properties: (i) $R_{j}\left(A_{j}\right)=1$ and $R_{j}(\emptyset)=0$; (ii) $B \subseteq D \Rightarrow R_{j}(B) \leq R_{j}(D)$ (monotonicity). The support $B \subseteq A_{j}$ of a nonadditive probability $R_{j}$ is a set verifying $R\left(B^{c}\right)=0$ and $\forall D C B(D \neq B), R\left(D^{c}\right)>0$. B may not be unique.
} 
that they are constants and $\left(R_{1}, R_{2}\right)$ are uniform squeezes of additive Nash strategies $\left(S_{1}, S_{2}\right)$ for a transformed game $\Gamma^{*}:\left(A_{1}, A_{2}, u_{1}^{*}, u_{2}^{*}\right)$, i.e., $R_{i}=\left(1-c_{j}\right) S_{i}$ for all events different of the entire set and $R_{i}=S_{i}=1$ otherwise, and where $u_{i}^{*}$ is defined in such a way that $E_{R_{j}} u_{i}=E_{S_{j}} u_{i}^{*}$ for $i, j=1,2$.

Theorem: [Dow \& Werlang, 1994]. Let $\Gamma:\left(A_{1}, A_{2}, u_{1}, u_{2}\right)$ be a finite 2 person game. For all $\left(c_{1}, c_{2}\right) \in[0,1]^{2}$ there exists a $N E U\left(R_{1}, R_{2}\right)$, such that $c_{1}$ is the uncertainty aversion coefficient associated to $R_{2}$ and $c_{2}$ the uncertainty aversion coefficient associated to $R_{1}{ }^{4}$

Proof: Dow \& Werlang (1994, p. 313, 314).

\section{Cournot Competition under Knightian Uncertainty.}

\subsection{The model.}

Consider a Cournot competitive oligopoly producing a unique homogenous and perfectly divisible good and composed of $N$ firms $(N \geq 2)$ having production techonologies, each one described by stable cost function $\phi_{j}\left(q_{j}\right)$ (i.e., with constant input prices; $j=$ $1,2, \cdots, N)$ and facing an inverse market demand $P=P(Q)$ if $0 \leq Q \leq \alpha(\alpha>0)$ and $P=0$ if $Q>\alpha$, where $Q=\sum_{j=1}^{N} q_{j}$ is the industry output $\left(q_{j} \geq 0\right)$. In order to make the analysis easy, suppose (without loss of generality) that functions $\phi_{j}$ and $P$ are $C^{2}$ (two times continuously differentiable) and assume that without uncertainty all marginal costs and marginal revenues are nondecreasing and non-increasing i.e., $\phi_{j}^{\prime \prime} \geq 0$ and $\left(R q_{j}\right)^{\prime \prime} \leq 0$ respectively $(j=1,2, \cdots, N) .{ }^{5}$ Firms bear nonsunken fixed costs (if any):

\footnotetext{
"The proof of the theorem relies on the definition of the Choquet's expected utility and may be understood from the description of the decision under uncertainty model, next Section 3.1.

${ }^{5}$ These properties ensure the existence of Cournot-Nash equilibrium in the game $\Gamma^{*}$ for each $N$. The restrictions that these assumptions impose on preferences and technologies are analysed in Sonnenschein \& Roberts (1977).
} 
$\phi_{j}(0)=0(j=1,2, \cdots, N)$ and each one can produce at the maximal production level $\alpha_{j} \geq \alpha /(N-1)$, in such a way that any group or $N-1$ of them may reduce price to zero. Under these assumptions, and given the supply of the $N-1$ other producers $Q_{(j)}=Q-q_{j}$, if producer $j$ chooses to produce $q_{j}$, his profit function will be:

$$
\Pi_{j}\left(q_{j} ; Q_{(j)}\right)=q_{j} \max \left\{P\left(q_{j}+Q_{(j)}\right), 0\right\}-\phi_{j}\left(q_{j}\right)
$$

which is a concave function for $q_{j} \in\left[0, \alpha_{j}\right]$ given $Q_{(j)}$. Consider now the noncooperative (Cournot) game for $N$ producers $\Gamma:\left(\left[0, \alpha_{1}\right],\left[0, \alpha_{2}\right] \cdots\left[0, \alpha_{N}\right], \Pi_{1}, \Pi_{2}, \cdots, \mathrm{II}_{N}\right)$ where each producer $j$ have to choose a production plan $q_{j}$ on $A_{j}=\left[0, \alpha_{j}\right]$ in oder to maximize its payoff function $\Pi$ under a Knightian uncertainty environment.

\section{Decision under uncertainy.}

Let $\Omega_{j}$ be the set of states of nature affecting the supply of rivals $Q_{(j)}\left(q_{j}\right)$ which is conjectured by a producer $j$, when he is taking the action $q_{j}$ over his set of choices $A_{j}=\left[0, \alpha_{j}\right]$. Let $\sigma\left(\Omega_{j}\right)$ be the $\sigma$ algebra of the events $B \subseteq \Omega_{j}$. Instead of defining conjectures directly over $A_{j}$ (as in Dow \& Werlang) we prefer to define nonadditive probabilities over sets $\Omega_{j}$, which can be different for two different producers. Define $R_{j}: \sigma \cdot\left(\Omega_{j}\right) \rightarrow[0,1]$ the nonadditive probability function (a capacity) giving the probability $R_{j}(B)$ for each event $B \in \sigma\left(\Omega_{j}\right)$.

Define now the reaction function conjectured by a producer $j$ as: $Q_{(j)}\left(\cdot ; q_{j}\right): \Omega_{j} \rightarrow R_{+}: \omega \rightarrow Q_{(j)}\left(\omega ; q_{j}\right)$. Given the action $q_{j} \in A_{j}$, producer $j$ conjectures that rivals jointly supply output $Q_{(j)}\left(\omega ; q_{j}\right)$ if the elementary event $\{\omega\}$ occurs. Assume $Q_{(j)}\left(\cdot ; q_{j}\right)$ is $\sigma\left(\Omega_{j}\right)$ measurable and let $\Pi_{j}\left(q_{j} ; Q_{(j)}\left(\omega ; q_{j}\right)\right)$ be the profit function when the producer takes the action $q_{j}$ and the event $\{\omega\}$ occurs. The 
nonadditive expected profit will be:

$$
E_{R_{j}}\left[\Pi_{j}\left(q_{j} ; Q_{(j)}\left(\cdot ; q_{j}\right)\right)\right]=\int_{\Omega_{j}} \Pi_{j}\left(q_{j} ; Q_{(j)}\left(\omega ; q_{j}\right)\right) R_{j}(d \omega) .
$$

Notice that this expected value is a function of the action $q_{j}$ taken by the producer $j$. According to G. Choquet (1955), the integration of a real-valued function w.r.t. a capacity, under some conditions (mesurability and boundedness), may be performed simply by the Riemann integration of the capacity over $R$, along the usual formula which allows to calculate the expectation of a random variable from its distribution function. In the present case, this gives: $E_{R_{j}} \Pi_{j}\left(q_{j} ; Q_{(j)}\left(\cdot ; q_{j}\right)\right)=\int_{-\infty}^{0}\left[R_{j}\left(\Pi_{j} \geq x\right)-1\right] d x+\int_{0}^{\infty} R_{j}\left(\Pi_{j} \geq x\right) d x .^{6}$

For this paper, and for all events different to $\Omega_{j}$, we use the uniform squeeze assumption (Dow \& Werlang, 1994): $R_{j}=\left(1-c_{j}\right) S_{j}$, where $S_{j}$ is an additive measure over $\Omega_{j}$ and $c_{j}\left(0 \leq c_{j} \leq 1\right)$ is the constant uncertainty aversion of the producer $j$. Notice that $R_{j}(B) \leq S_{j}(B) \leq c_{j}+R_{j}(B)$ for all $B \neq \Omega_{j}$ (see note 6 below) and $R_{j}\left(\Omega_{j}\right)=S_{j}\left(\Omega_{j}\right)=1$. Under this assumption, the above Choquet's expected profit becomes: $E_{R_{j}} \Pi_{j}\left(q_{j} ; Q_{(j)}\left(\cdot ; q_{j}\right)\right)=$ $\int_{-\infty}^{\min \Pi_{j}}\left[R_{j}\left(\Pi_{j} \geq x\right)-1\right] d x+\int_{\min \Pi_{j}}^{0}\left[R_{j}\left(\Pi_{j} \geq x\right)-1\right] d x+$ $\int_{0}^{\infty} R_{j}\left(\Pi_{j} \geq x\right) d x=0+\int_{\min \Pi_{j}}^{0}(-1) d x+\int_{\min \Pi_{j}}^{\infty} R_{j}\left(\Pi_{j} \geq x\right) d x=$ $\min _{\omega \in \Omega_{j}} \Pi_{j}\left(q_{j} ; Q_{(j)}\left(\omega ; q_{j}\right)\right)+\left(1-c_{j}\right) \int_{\min \Pi_{j}}^{\infty} S_{j}\left(\Pi_{j} \geq x\right) d x$. Now,

$$
\begin{gathered}
E_{S_{j}} \Pi_{j}\left(q_{j} ; Q_{(j)}\left(\cdot ; q_{j}\right)\right)-\min _{\omega \in \Omega_{j}} \Pi_{j}\left(q_{j} ; Q_{(j)}\left(\omega ; q_{j}\right)\right) \\
=\int_{\min \Pi_{j}}^{\infty} S_{j}\left(\Pi_{j} \geq x\right) d x .
\end{gathered}
$$

${ }^{6}$ If the capacity is convex, i.e. $R_{j}(B \cup D)+R_{j}(B \cap D) \leq R_{j}(B)+R_{j}(D) ; \forall B, D \subseteq \Omega_{j}$, then producer $j$ is uncertainty-averse, and the above nonadditive expected utility may be alternatively calculated as the infimum of additive expected utilities taken from probability measures belonging to the core of $R_{j}: \operatorname{Core}\left(R_{j}\right) \equiv\left\{S: \Omega_{j} \rightarrow[0,1]\right.$ additive: $\left.S(B) \geq R_{j}(B) ; \forall B \subseteq \Omega_{j}\right\}$ (see Schmeidler, 1989). In the present case we would deal with, $E_{R_{j}} \Pi_{j}\left(Q_{(j)}\left(\cdot ; q_{j}\right) ; q_{j}\right)=$ inf $_{S \in \operatorname{Core}\left(R_{j}\right)}\left\{E_{s} \Pi_{j}\left[\left(Q_{(j)}\left(\cdot ; q_{j}\right) ; q_{j}\right)\right]\right\}$. 
Thus, by substituting the lhs in the last term of the former equation we obtain:

$$
\begin{aligned}
& E_{R_{j}} \mathrm{II}_{j}\left(q_{j} ; Q_{(j)}\left(\cdot ; q_{j}\right)\right)=c_{j} \min _{\omega \in \Omega_{j}} \mathrm{II}_{j}\left(q_{j} ; Q_{(j)}\left(\omega ; q_{j}\right)\right) \\
& \quad+\left(1-c_{j}\right) E_{S_{j}} \mathrm{II}_{j}\left(q_{j} ; Q_{(j)}\left(\cdot, q_{j}\right)\right)
\end{aligned}
$$

In order to give the minimum value for the first term on the rhs of this equation, producer $j$ conjectures that the subset $\left\{\omega \in \Omega_{j}\right.$ : $\left.Q_{(j)}\left(\omega ; q_{j}\right)=\alpha ; \forall q_{j} \in A_{j}\right\}$ is nonempty (the $N-1$ competitors, acting as a coalition or not, should reduce his residual demand to zero). In this case, the first term on the rhs of (3.0) anulls and, from that equation, producer $j$ must endure a loss $-\phi_{j}\left(q_{j}\right)$. Thus, noting $\operatorname{II}_{j}^{*}\left(q_{j}, Q_{(j)}\left(\omega, q_{j}\right)\right)=\left(1-c_{j}\right) \operatorname{II}_{j}\left(q_{j}, Q_{(j)}\left(\omega ; q_{j}\right)\right)-c_{j} \phi_{j}\left(q_{j}\right)$ and by using (3.0) we arrive to the following payoff function:

$$
\Pi_{j}^{*}\left(q_{j} ; Q_{(j)}, c_{j}\right)=\left(1-c_{j}\right) q_{j} \max \left\{P\left(q_{j}+Q_{(j)}\right) ; 0\right\}-\phi_{j}\left(q_{j}\right)
$$

\section{Mixed strategies, pure strategies and NEU.}

For any producer $j$ who takes the action $q_{j}$, and does assess his conjecture $Q_{(j)}(\cdot, q)$ through a superadditive probability $R_{j}$ that is an uniform squeeze of an additive probability $S_{j}$, the identity $E_{R_{j}} \operatorname{II}_{j}\left(q_{j} ; Q_{(j)}\left(\cdot ; q_{j}\right)\right)=E_{S_{j}} \operatorname{II}_{j}^{*}\left(q_{j} ; Q_{(j)}\left(\cdot, q_{j}\right)\right)$ means that he should find equivalent the two games, $\Gamma_{N}$ : $\left(A_{1}, A_{2}, \cdots, A_{N}, \Pi_{1}, \mathrm{II}_{2}, \cdots, \mathrm{II}_{N}\right)$ (under uncertainty) and $\Gamma_{N}^{*}$ : $\left(A_{1}, A_{2}, \cdots, A_{N}, \mathrm{II}_{1}^{*}, \mathrm{II}_{2}^{*}, \cdots, \mathrm{II}_{N}^{*}\right)$ (with certainty), where $\mathrm{II}_{j}^{*}$ is given with (3.1). ${ }^{7}$ Of course, capacities $R_{j}$ and probabilities $S_{j}$ are not strategies because they are not defined over the production sets

\footnotetext{
${ }^{7}$ In the prospect of incentive equilibrium models of moral hazard type, one might think of that coefficient $c_{j}$ in the objective finction $\Pi_{j}^{*}$ could measure the inability assigned by the principal (the owner $j$ ) to the agent (the manager) for implementing the profit maximization of the firm
} 
$A_{j}$. However, since $Q_{(j)}\left(\cdot ; q_{j}\right)$ are real valued and are assumed to be $\sigma\left(\Omega_{j}\right)$-measurable, they will induce probability functions over the sets $\left[0, \sum_{i \neq j} \alpha_{i}\right]$, say $\Sigma_{(j)}$, such that for all $B \subseteq\left[0, \sum_{i \neq j} \alpha_{i}\right]$, $\Sigma_{(j)}\left(B ; q_{j}\right)=\int_{Q_{(j)}\left(B ; q_{j}\right)}^{-1} S_{j}(d \omega)$. Then the uniform squeeze assumption applies on $\Sigma_{(j)}$ and the capacity $P_{(j)}$ is defined accordingly: $P_{(j)} \equiv\left(1-c_{j}\right) \Sigma_{(j)}$ (for any set different of the entire set and $P_{(j)}=\Sigma_{(j)}$ otherwise). Now $P_{(j)}$ and $\Sigma_{(j)}$ may be viewed respectively, as mixed strategies for games $\Gamma_{N}$ and $\Gamma_{N}^{*}$. Notice that $\Sigma_{(j)}$ (and $\left.P_{(j)}\right)$ depend on $q_{j}$, that is to say that there is one mixed strategy for each choice $q_{j}$ of the producer. If one wants to consider CournotNash equilibrium in mixed strategies, the application of the Dow \& Werlang's definition for NEU and the existence theorem described in Section 2 for a game with $N=3,4, \cdots$ players would require some adaptations.

Firstly, for the game $\Gamma_{N}:\left(A_{1}, A_{2}, \cdots, A_{N}, \Pi_{1}, \Pi_{2}, \cdots, \Pi_{N}\right)$ we say that the sequence of mixed nonadditive strategies $P_{(1)}, P_{(2)}, \cdots, P_{(N)}$ is a Nash equilibrium under uncertainty (NEU) if there are supports $\operatorname{supp}\left(P_{(1)}\right), \operatorname{supp}\left(P_{(2)}\right), \cdots, \operatorname{supp}\left(P_{(N)}\right)$ such that if each producer $j$ assigns to the conjecture $Q_{(j)}\left(\omega ; q_{j}\right)=\sum_{i \neq j}^{n} q_{i}$ a positive probability $\left(P_{(j)}>0, j=1,2, \cdots, N\right)$, then quantities $q_{i}(i=1,2, \cdots, N, i \neq j)$ maximizes the expected utility of the producer $i$ given that $P_{(i)}$ is the nonadditive probability function for assessing the joint supply of rivals conjectured by the producer $i$ (the converse must also be true). Formally:

(Cournot strategy) instead of the maximin strategy (inactivity). According such models, (see Fershtman \& Judd, 1987; Sklivas, 1987) $c_{j}$ should then be a parameter to be chosen by the principal in a two-stage game where in the second stage the agent chooses quantitites. However, in our model the coefficient is a given feature of the agent (the manager in place) and only the second stage occurs. Therefore, it does not conform with such an interpretation and there is no reason to distinguish here the producer from the manager.

Revista de Econometria 18 (2) Novembro 1998 


$$
\begin{gathered}
\forall j, \quad\left\{\omega \in \Omega_{j}: Q_{(j)}\left(\omega ; q_{j}\right)=\sum_{i \neq j}^{n} q_{i}\right\} \in \operatorname{supp}\left(P_{(j)}\right) \Longleftrightarrow \\
q_{i} \in \underset{q \in A_{i}}{\arg \max } E_{P_{(i)}} \Pi_{i}\left(q ; Q_{(i)}\right), \quad \forall i(i \neq j) .
\end{gathered}
$$

As we can realize, this definition is a straightforward extension for more than two players of the Dow \& Werlang's definition. Here, mixed strategies are optimal if each one can support all aggregate rival's supplies which are competitive (in the sens that individual quantities are optimal);

Secondly, from the above definition it is clear that NEU's existence theorem of Dow \& Werlang applies for the game $\Gamma_{N}$. Indeed, the uniform squeeze assumption ensures that if the sequence of joint mixed strategies $\Sigma_{(1)}, \Sigma_{(2)}, \cdots, \Sigma_{(N)}$ is a Nash equilibrium for the standard game $\Gamma_{N}^{*}:\left(A_{1}, A_{2}, \cdots, A_{N}, \Pi_{1}^{*}, \Pi_{2}^{*}, \cdots, \Pi_{N}^{*}\right)$, then $P_{(1)}, P_{(2)}, \cdots, P_{(N)}$, will be a NEU for $\Gamma_{N}$, because $P_{(j)}=(1-$ $\left.c_{j}\right) \Sigma_{(j)}$, and the identity $E_{P_{(j)}} \Pi_{j}\left(q_{j} ; Q_{(j)}\right)=E_{\Sigma_{(j)}} \Pi_{j}^{*}\left(q_{j} ; Q_{(j)}\right)$ holds. Since NEU requires personal conjectures $Q_{(j)}$ must match (in probability) actual aggregate suplies $\sum_{i \neq j}^{n} q_{i}$ which are competitive, the equilibrium hinges on a rational expectation hypothesis. ${ }^{8}$

The above definition of NEU implies that each player $j$ is taking pure strategies in the game $\Gamma_{N}$. Pure strategies in this context are credible. ${ }^{\vartheta}$ Furthermore, by the definition of NEU, $E_{P_{(j)}} \Pi_{j}\left(q_{j} ; Q_{(j)}\right)$ is constant over any set $\left\{\omega \in \Omega_{j}: Q_{(j)}\left(\omega ; q_{j}\right)=\sum_{i \neq j}^{n} \hat{q}_{i}\left(q_{j}\right)\right\} \in$

\footnotetext{
${ }^{8} \mathrm{~A}$ more complete account of the rational expectation hypotheses used in general equilibrium theory can be found in Grossman (1981) and Radner (1989).

${ }^{9}$ An alternative approach would be to assume that producers randomize their individual choices to implement mixed strategies. However, as note Dow \& Werlang (1994, p. 312) models of Knightian uncertainty are not suitable for describing this interpretation. Notice that in the AnscombeAumann framework (a two stage approach) it is shown that agents with Choquet Expected Utility (CEU) preferences have strict preference for randomized (mixed) strategies (Sarin \& Wakker, 1992; Eichberger \& Kelsey, 1996). However, the dominance of randomized strategies is not im-
} 
$\operatorname{supp}\left[P_{(j)}\left(q_{j}\right)\right]$ where each $\hat{q}_{i}\left(q_{j}\right)$ is the best response (in pure strategy) of a rival $i \neq j$ in the game $\Gamma_{N}^{*}$, given the choice $q_{j}$ of the producer $j$. Therefore, the best individual responses $\widehat{q}_{1}, \widehat{q}_{2}, \cdots, \widehat{q}_{N}$ are obtained by the maximization of $E_{\Sigma_{(j)}} \Pi_{j}^{*}\left(q_{j} ; Q_{(j)}\left(\cdot, q_{j}\right), c_{j}\right)$ w.r.t. $q_{j}$ from the equation system (2.1) for $j=1,2, \cdots, N$. Finally, the optimal quantities $\widehat{q}_{1}, \widehat{q}_{2}, \cdots, \widehat{q}_{N}$ define implicitly optimal mixed strategies consistent with the previous beliefs, which are the NEU for the game $\Gamma_{N}$ say, $\widehat{P}_{(1)}, \widehat{P}_{(2)}, \cdots, \widehat{P}_{(N)}$.

The dependence of conjectured rival's supply $Q_{(j)}$ on the producer quantities $q_{j}$ in the present model provides a basis for the static theory of the conjectural variations $d Q_{(j)} / d q_{j}$ firstly used by A.L. Bowley (1924) and named by R. Frisch (1933). According to the Cournot assumption of independent behavior, conjectural variations are zero. So, in the sequel it is assumed that the competitive equilibrium $\widehat{q}_{1}, \widehat{q}_{2}, \cdots, \widehat{q}_{N}$ occurs when each optimal strategy $\widehat{P}_{(j)}$ for a player $j$ supports the set $\left\{\omega \in \Omega_{j} ; Q_{(j)}(\omega)=\right.$ $\left.\sum_{i \neq j}^{N} \widehat{q}_{i}\left(q_{j}\right) ; \forall q_{j} \in A_{j}\right\}$. Under the Cournot assumption the additive distributions $\Sigma_{(j)}$ no longer depend on $q_{j}$. Therefore, the maximum of $E_{\Sigma_{(j)}} \Pi_{j}^{*}\left(q_{j} ; Q_{(j)}\left(\cdot, q_{j}\right), c_{j}\right)$ w.r.t. $q_{j}$ is obtained by maximizing the rhs of (3.1) under the restriction $Q_{(j)}=\sum_{i(i \neq j)} q_{i} \cdot{ }^{10}$

\section{Cournot-Nash equilibrium for $\Gamma_{N}^{*}$.}

Functions $\Pi_{j}^{*}\left(q_{j} ; \sum_{i(i \neq j)} q_{i} ; c_{j}\right)$ are continuous transformations of $\Pi_{j}$ and preserve their properties ( $C^{2}$ class, bounded and concave w.r.t. $q_{j}$ and $c_{j}$ ). The production sets $\left[0, \alpha_{j}\right]$ are compact and convex

plied for CEU preferences in a Savage framework (a one stage approach); see Eichberger \& Kelsey (1996). The uniform squeeze of an additive distribution hypothesis made in the Dow \& Werlang approach allows one to calculate CEU over the ambiguous events in one stage through additive strategies in the game $\Gamma^{*}$ (with payoff given by equation (3.1)). Hence, the pure strategies obtained here may be the best response of the producers.

${ }^{10}$ For the present model, Boff (1998) shows that producers are dealing with consistent (and collusive) conjectural variations (i.e., which are implicitly fullfilled and positive). 
sets of $R$, and then a fixed point theorem applies on the first order conditions system of the maximization problem (at any vector $c \in$ $\left.[0,1]^{N}\right)$ in oder to ensure the existence of a Cournot-Nash equilibrium for the game $\Gamma_{N}^{*}$. Thus, for a firm $j(j=1,2, \cdots, N)$ which chooses quantities $q_{j}$ that maximizes its payoff function (3.1) given the supply $\sum_{i(i \neq j)} q_{i}$ of its competitors we have the first order condition:

$$
\frac{\partial \Pi_{i}^{\dot{ }}}{\partial q_{j}}-\left(1-c_{j}\right)\left[q_{j} P^{\prime}\left(q_{j}+\sum_{i(i \neq j)} q_{i}\right)+P\left(q_{j}+\sum_{i(i \neq j)} q_{i}\right)\right]-\phi_{j}^{\prime}\left(q_{j}\right)=0
$$

The solution for this system is the pair of vectors say, $(\widehat{q}, c)$ and equations (3.2) are necessary and sufficient to provide a maximum for $\Pi_{j}^{*}, j=1,2, \cdots, N$.

The implicit function theorem is then fully assumed to apply at $(\widehat{q}, c)$ in such way that the solution can be implicitly solved for each $j$ by functions $q_{j}(c)$, which are continuously differentiable in the whole range $c \in[0,1)^{N}$. Note $Q(c)=\sum_{j=1}^{N} q_{j}(c)$ for the equilibrium industry output (we delete the hat " to simplify notations). If $c_{j}=1$ the optimal solution for producer $j$ is $q_{j}(c)=0$. In the sequel the set $[0,1)^{N}$ is restricted for the uncertainty aversion vectors where optimal positive productions $\left\{q_{j}(c)>0\right\}$ yields nonnegative profits for every producer:

$$
\begin{aligned}
C_{N} & =\left\{c \in[0,1)^{N}: \Pi_{j}(c)=q_{j}(c) P(Q(c))-\phi_{j}\left(q_{j}(c)\right) \geq 0\right. \\
& j=1,2, \ldots, N\} .
\end{aligned}
$$

As far as section 4.3, we assume that for a given $N, \Pi_{j}(0)>0$, $j=1,2, \cdots, N$ that is to say, without uncertainty, all firms make positive profits. Hence, $C_{N}$ is non empty $\left(0 \in C_{N}\right)$ and since price $P$ and costs $\phi_{j}$ are functions belonging to the $C^{2}$ class, we may assume $C_{N}$ is a connected open subset of $[0,1)^{N}$. Given $N$, if the regularity 
condition on the Jacobian matrices associated to each one equation (3.2) holds, the Cournotian equilibrium quantities $q_{j}(c)$ are functions belonging to the class $C^{1}$ over $C_{N}$. Of course, the set $C_{N}$ will depend on $N$ and on the technological and demand parameters as well.

At some extent, coefficients $c_{i}$ shall be viewed either as indicators for the behavioral attitude of the agents facing uncertainty, or as signs of their lack of information since the uncertainty may be partially caused by missinformation. In the former sense, the parameters relies closely on the preferences of the producers.

\subsection{Comparative statics.}

Now we will exam more closely the effects of uncertainty aversion variations on the equilibrium quantities $q_{j}\left(c_{1}, \cdots, c_{N}\right)$, $q_{(j)}\left(c_{1}, \cdots, c_{N}\right)$ and output $Q(c)$. Recall that $q_{j}\left(c_{1}, \cdots, c_{N}\right)$ must be interpreted as conjectural (or virtual) equilibriums only, since the actual calculations presuppose omniscience among producers, which is not likely in the real world. ${ }^{11}$ Of course, quantities and output are also function of $N$ (see section 4 ) that is not presently made explicit to avoid overloading notations.

The differentiation on both sides of the equation system (3.2) w.r.t. $c_{1}, c_{2}, \cdots, c_{N}$ enables to state the following proposition:

Proposition 1: Take the Cournot competition model under Knightian uncertainty as presented in section 3.1. Let $c_{i}, c_{j}(i \neq j)$ be

\footnotetext{
${ }^{11}$ Notice that $\left[q\left(c_{1}, c_{2}, \cdots, c_{N}\right), P(Q(c))\right]=\left[\left(q_{1}\left(c_{1}, \cdots, c_{N}\right), \cdots, q_{N}\left(c_{1}, \cdots, c_{N}\right), P(Q(c))\right]\right.$ is a pooled information equilibrium, meaning it only can be calculated if the (private) information vector (not related with the production), $c^{\prime}=\left(c_{1}, \cdots, c N\right)$ is known by all producers. Producers observe actual equilibrium production vector $q^{*}$ and the market price $P^{*}$. If the system $q(c)=q^{*}$ is invertible, i.e., if there exists $c^{*}=q^{-1}\left(q^{*}\right)$, and if $P^{*}=P\left(Q\left(c^{*}\right)\right)$, and if $P^{*}=P\left(Q\left(c^{*}\right)\right)$, then $q(c)$ is a fully revealing equilibrium since the market itself reveals to agents all non-productive private information (held before by individual producers). In this case, $q(c)$ can be viewed as a rational expectation equilibrium. See Mas-Colell \& alii (1995, p. 721) and Radner (1989).
} 
the projections on the $i^{\text {th }}$ and $j^{\text {th }}$ axis of the vector $c \in C_{N}$. The uncertainty aversion effects on the Cournot-Nash equilibrium quantities $\left(q_{j}\right)$ for a firm $j$ matching the game $\Gamma_{N}^{*}$ and on the equilibrium industry output $(Q)$, are given by the following equations:

$$
\begin{aligned}
& \sigma_{j}(c)=\frac{a_{j}\left[\left(1-c_{j}\right) P^{\prime}-\phi^{\prime \prime}\right]+P^{\prime}\left[q_{j}(c) P^{\prime}+P\right]}{P^{\prime \prime}\left[Q P^{\prime}\left(1-c_{j}\right)-Q(j) \phi^{\prime \prime}\right]+P^{\prime}\left[\left(1-c_{j}\right)(N+1) P^{\prime}-N \phi^{\prime \prime}\right]} \\
& \frac{\partial q_{j}}{\partial c_{j}}=\frac{q_{j} P^{\prime}+P-\left(1-c_{j}\right)\left[q_{j} P^{\prime \prime}+P\right] \sigma_{j}(c)}{\left(1-c_{j}\right) P^{\prime}-\phi_{j}^{\prime \prime}} \\
& \frac{\partial q_{i}(c)}{\partial c_{j}}=-\frac{\left(1-c_{i}\right)\left[q_{i}(c) P^{\prime \prime}+P^{\prime}\right] \sigma_{j}(c)}{\left(1-c_{i}\right) P^{\prime}-\phi_{i}^{\prime \prime}}
\end{aligned}
$$

where $\sigma_{j}(c)=\frac{\partial Q(c)}{\partial c_{j}}$ and $\alpha_{j}=\sum_{i(i \neq j)} \frac{1}{1-c_{j}} \phi_{i}^{\prime \prime}\left(q_{i}\right) \frac{\partial q_{i}}{\partial c_{j}}$.

\section{Proof: See Appendix.}

Here and later on we omit the arguments $Q(c)$ and $q_{i}(c)$ in the notation of $P$ and $\phi_{j}$ functions and their derivatives (respectively). Equations (3.3)-(3.5), show that uncertainty aversion effects on production at equilibrium depend directly only on the returns to scale of factors $\left(\phi_{j}^{\prime \prime}\right)$ disregarding whether there is fixed costs (sunken or not) in the firm. ${ }^{12}$ Without any further additional hypotheses, nothing can be said about the signs of the above derivative.

Under constant return to scale technologies assumption $\left(\phi_{j}^{\prime \prime}=\right.$ $0 ; j=1,2, \cdots, N)$ the marginal effect of the uncertainty aversion on the output (3.3) becames:

$$
\sigma_{j}(c)=\frac{q_{j}(c) P^{\prime}+P}{\left(1-c_{j}\right)(N+1)\left[\frac{Q(c)}{N+1} P^{\prime \prime}+P^{\prime}\right]}
$$

\footnotetext{
${ }^{12}$ Recall that, in the case of nonsunken fixed costs, the nonnegative profit restriction bounds the size of the industry to a number of firms $N_{\omega}$ which will depend on fixed costs (negatively). However, the game $\Gamma$ with $N_{\omega}$ players have a unique pure strategy equilibrium; hence, it doesn't support any uncertainty.
} 
Throughout the paper, we will refer to the inequality $\frac{Q(c)}{N+1}$ $P^{\prime \prime}(Q(c))+P^{\prime}(Q(c))<0$ as the "modified decreasing marginal revenue" condition (noted MDMR). Notice that this condition is similar to the familiar requirement $q_{j} P^{\prime \prime}+P^{\prime}<0$ for the stability of the equilibrium, (an increase in rivals' output lowers firm $j$ 's marginal revenue). The MDMR condition is endogenous. However, it is allways fulfilled for (i) concave or linear market demand; (ii) convex market demand with constant price-elasticity (e.g., $P(Q)=Q^{-\delta} ; 0<\delta<1$ as below) or any other function with a smooth curvature. Therefore, the results presented in this paper are covered by a large family of market demand functions exhibiting the MDMR property for any $c \in C_{N}$.

Corollary 1: Under constant returns to scale technologies, for vectors $c \in C_{N}$ verifying the MDMR condition the derivatives (3.3)(3.5) of proposition 1 have the following signs:

$$
\begin{aligned}
\sigma_{j}<0 ; \operatorname{sign}\left(\frac{\partial q_{j}(c)}{\partial c_{j}}\right) & =\operatorname{sign}\left[\frac{Q}{N}\left(1-r_{j}\right) P^{\prime \prime}+P^{\prime}\right] ; \operatorname{sign}\left(\frac{\partial q_{i}(c)}{\partial c_{j}}\right) \\
& =-\operatorname{sign}\left[q_{i} P^{\prime \prime}+P^{\prime}\right]
\end{aligned}
$$

where $r_{j}=q_{j} / Q$ is the market share of firm $j$.

Proof: See Appendix.

Notes:

i) With concave market demand (i.e., $P^{\prime \prime} \leq 0$ ) we have $\frac{\partial q_{i}(c)}{\partial c_{j}}>0$, $(i \neq j)$ and $\frac{\partial q_{j}(c)}{\partial c_{j}}<0$

ii) In the convex market demand case $\left(P^{\prime \prime} \geq 0\right)^{13}$ a nonincreasing

\footnotetext{
${ }^{13}$ Recall that the convexity condition for the aggregate demand is not directly related to the convexity property of the consumers' preferences, since the condition depends on the sign of the third derivative of the utility function only (see Mas-Collel et alii, 1995, section 10c). However, this might restraint the set where the MDMR condition holds, as we mentionned above.
} 
marginal revenue hypothesis $\left(P q_{j}\right)^{\prime \prime} \leq 0$ can also be written as $\left(\frac{1}{2} \max q_{j}\right) P^{\prime \prime}+P^{\prime} \leq 0$. Hence, the nonincreasing marginal revenue assumption implies the MDMR condition if $\max _{i \leq j \leq N} r_{j}>$ $2 / N+1$ and the assumption is implyied by MDMR otherwise. In this case, under the conditions of the corollary 1 , the sign of $\frac{\partial q_{j}(c)}{\partial q_{j}}$ is always negative for firms $j$ that are not too small $\left(r_{j} \geq 1 / N+1\right)$

iii) Under a symmetric variation in the uncertainty coefficients for all producers, the total effect on the optimal quantities of a firm $\mathrm{j}$ is given by (using (3.4)-(3.5)):

$$
\chi_{j}(c)=\sum_{1 \leq i \leq N} \frac{\partial q_{j}(c)}{\partial c_{i}}=\frac{\partial q_{j} P^{\prime}+P-\left(1-c_{j}\right)\left[q_{j} P^{\prime \prime}+P^{\prime}\right\} \sum_{1<i<N} \sigma_{i}(c)}{\left(1-c_{j}\right) P^{\prime}-\phi^{\prime \prime}}
$$

Then, under the conditions of the corollary 1 , we obtain $\chi_{j}<$ 0 when $q_{j} P^{\prime \prime}+P^{\prime} \geq 0$ and the sign is ambiguous otherwise $\left(q_{j} P^{\prime \prime}+P^{\prime}<0\right)$

iv) When $P(Q)=Q^{-\delta}(0<\delta \leq 1)$ with constant price-elasticity, the MDMR condition is fulfilled for all $c \in[0,1)$. Then, under constant returns to scale assumptions $\left(\phi_{i}^{\prime \prime}=\phi_{j}^{\prime \prime}=0\right)$, corollary 1 applies and a proper substitution of $P, P^{\prime}$ and $P^{\prime \prime}$ in (3.6) and (3.4)-(3.5) gives:

$$
\begin{aligned}
\sigma_{j} & =\frac{Q}{N+1}\left(\frac{1}{1-c_{j}}\right)\left(r_{j}-\frac{1}{\delta}\right) \\
\frac{\partial q_{j}}{\partial c_{j}} & =\left(\frac{\alpha}{N+1}\right)\left(\frac{1}{1-c_{j}}\right)\left(r_{j}-\frac{1}{\delta}\right)\left(N+(1+\delta) r_{j}\right) \\
\frac{\partial q_{i}}{\partial c_{j}} & =-\frac{(\delta+1) Q}{(N+1)\left(1-c_{j}\right)}\left(r_{i}-\frac{1}{\delta}\right)\left(r_{j}-\frac{1}{1+\delta}\right) .
\end{aligned}
$$


So, since $r_{j} \leq \frac{1}{\delta}$ we have, successively: $\sigma_{j} \leq 0, \frac{\partial q_{j}}{\partial c_{j}} \leq 0$ and $\operatorname{sign}\left(\frac{\partial q_{i}}{\partial c_{j}}\right)-\operatorname{sign}\left(r_{j}-\frac{1}{1+\delta}\right)$.

\subsection{Large number of firms.}

Consider now a sequence of games $\Gamma_{N}$ (and $\Gamma_{N}^{*}$ ) for integers $N \geq 2$. We are looking for the effects of uncertainty parameter variations on the equilibrium quantities $q_{j}$ as the number of firms matching the one-shot game $\Gamma_{N}$ increases. For this reason we will assume that the games $\Gamma_{N}^{*}$ are independent and that for each $N$ (given exogenously), there is no free entry. In the case there is fixed costs (nonsunken) for operating in the industry, we assume the entry of a new firm in the game follows an increase in the market size, in such a way that, at equilibrium the inequalities $P(Q) \geq \max _{2 \leq j \leq N}\left\{\frac{\phi_{j}\left(q_{j}\right)}{q_{j}}\right\}$ al ways holds for $N=1,2, \cdots, N$ and $c \in C_{N}$.

Consider the case of nonidentical firms $\left(\phi_{i} \neq \phi_{j}\right)$ with asymmetric uncertainty aversion parameters for the producers $\left(c_{i} \neq c_{j}\right)$, $j=1,2, \cdots$. Assume first, that the uncertainty parameters $c_{i}$ do not change as the number $N$ of players playing $\Gamma_{N}^{*}$ increases. Assume also a finite market size, as $N \rightarrow \infty$. In this case, the industry output $(Q)$ will be bounded. If the sums $a_{j}(c)=\sum_{i(\neq j)}\left(\frac{1}{1-c_{i}}\right) \phi_{i}^{\prime \prime} \frac{\partial q_{i}(c)}{\partial c_{j}}$ are also bounded $(\forall j=1,2, \cdots),{ }^{14}$ then a quick inspection of (3.5) shows that $\sigma_{j} \rightarrow 0$ as $N \rightarrow \infty(\forall j)$. Therefore, from (3.4) and (3.5) we will have: $\frac{\partial q_{j}}{\partial c_{j}} \rightarrow \frac{q_{j} R^{\prime}+R}{\left(1-c_{j}\right) R^{\prime}-\phi_{j}^{\prime \prime}}<0$ and $\frac{\partial q_{i}(c)}{\partial c_{j}} \rightarrow 0$.

Comment: For high industry sizes, increases in the uncertainty aversion parameter for any producer only reduces his own equilibrium quantities. So, an increasing number of firms tends to reduce

\footnotetext{
${ }^{11}$ The assumption is trivially verified when technologies exhibit constant returns to scale $\left(\phi_{j}^{\prime \prime}=0\right)$.
}

Revista de Econometria 18 (2) Novembro 1998 
virtual depressive effects on aggregate production of a rise in competitive uncertainty (henceforth, on the rise of the equilibrium market price). At the same time, the externality effect of a marginal rise in the uncertainty aversion of an individual producer on the quantities produced by any other producer vanishes: as $N$ increases the market share of firms becomes smaller and the external effect of additional uncertainty aversion among a greater number of producers becomes negligible. However, one might argue that the uncertainty aversion coefficients $c_{i}$ should decrease as the number $N$ of the matching firms increases. In this case, under a finite market size assumption, for sequences $\left\{c_{(N)}^{*}\right\}$ converging to zero as $N \rightarrow+\infty$, the derivatives $\frac{\partial q_{j}}{\partial c_{j}}$ given in (3.4) also vanish. ${ }^{15}$

\subsection{Lerner index.}

From the first order condition for the maximization of $\Pi_{j}^{*}$ in (3.2) we have: $r_{j}=\varepsilon\left[\lambda_{j}-c_{j}\right] /\left(1-c_{j}\right)$ where $\lambda_{j}-\left(P-\phi_{j}^{\prime}\right) / P$ is the price-cost Lerner index and $\varepsilon=-\frac{P}{Q(c) P^{\prime}}$ is the price-elasticity of the market demand (in modulus). For high values of $N$ and uncertainty aversion vectors $c$, the quantities produced by an individual firm $j$ are negligible with respect to the industry output; in such cases $r_{j} \simeq 0$ would imply $c_{j} \simeq \lambda_{j}(c)$. So, when the competing firms are small, the price-cost margins they obtain are each one closer to the uncertainty aversion parameters of the producers. In the symmetric case, $r=1 / N$ and therefore, $c=(N \varepsilon \lambda-1) /(N \varepsilon-1)$. For high values of $N$, when identical firms operate all with a constant returns to scale, the common parameter $c$ defines a market prize rate for the uncertainty that the producers would add to the competitive price.

\footnotetext{
${ }^{15}$ For instance, let $c_{j}^{*}=c_{j}^{N}\left(0<c_{j}<1\right)$ and $q_{j}^{*}\left(c_{j}^{*}, c_{(j)}^{*}\right.$ be the corresponding Cournot equilibrium for each $N, j=1,2, \cdots, N$. When $N \rightarrow+\infty$, as $q_{i}$ are $C^{1}$, we have $q_{j}^{*}\left(c_{j}^{*}, c_{(j)}^{*}\right) \rightarrow q_{j}(0,0)$ and, of course, the derivatives $\left.\frac{\partial q_{j}^{*}}{\partial c_{j}}\left(c_{j}^{*}, c_{(j)}^{*}\right)=\frac{\partial q_{j}}{\partial c_{j}}\left(c_{j}^{*},{ }_{(j)}^{*}\right)\right) N c_{j}^{N-1}$ also vanish $\left(N c_{j}^{N-1}\right.$ tends to 0 as $N \rightarrow \infty)$.
} 
Indeed, if $P_{0}$ stands for the competitive price a $P_{0}=\phi^{\prime}$ constant leads to a coefficient implicitly defined by $c \simeq \lambda_{0}(c)=\frac{P-P_{0}}{P_{0}}$, where $P=P(Q(c))$.

\section{Identical Firms.}

The conspicuous results of the present model are obtained under symmetric assumptions. Suppose then the producers have access to and actually employ the same production technology $\left(\phi_{i}=\phi\right)$. A Knightian uncertainty environment can also be viewed as a situation where agents do not have enough information to proceed to a proper description of the states of nature affecting rival's decisions. Hence, they cannot asses their guesses about all possible joint supply of rivals by an unique (subjective) probability distribution function. ${ }^{16}$ As it was noticed above, the uncertainty aversion $c_{j}$ can therefore be taken as an indicator for the missing information of the agent $j$ regarding the supply of his $N-1$ competitors. Suppose then producers are all symmetrically uncertainty averse (or, assume they use the same information amount) that is, $c_{j}=c(j=1,2, \cdots, N)$. In order to enrich the analysis of the symmetric case, we assume that the firms bear a fixed cost $k(k>0)$ eventually nonsunken. The existence of this fixed cost imposes a limit for the number $N$ of firms which are able to operate with nonnegative profits. Let $N_{\omega}$ be an industry size annulating the profit of firms without uncertainty, that is, such that $N_{\omega} \in \max \{N: \operatorname{II}(0, N) \geq 0\}$ and note $\left[N_{\omega}\right]$ for its integer part ( $\omega$ stands for the parameters of the model).

Under these assumptions, we will principally show in this section: (a) how Cournotian competition among a fixed number $N$ of uncertainty averse producers may generate a cooperative (collusive)

\footnotetext{
${ }^{16}$ On the conditions for setting the equivalence between the (present) nonadditive approach and this (so-called) maximin approach, see Schmeidler (1989), Gilboa \& Schmeidler (1989) and for an introductory exposition, Simonsen \& Werlang (1991).
} 
outcome for the industry; and (b) under a free-entry regime, how uncertainty aversion of the producers acts preventing market power for the individual firms.

\subsection{Closed industry.}

Hereafter, the industry size $N$ is made explicit in the notations for the equilibrium quantities $\left(q_{i}\right)$ and output $(Q)$ functions (as well as in the other functions related to them) and we assume that they are continuously differentiable with respect to this argument whenever $N$ is treated as a continuous variable. Thus, under the courrent assumptions, all equilibrium firms' quantities are identical to $q(c, N)$ and the industry output is $N q(c, N)$. We have also $\sigma_{j}=\sigma$ and $\chi_{j}=\chi$ for all $j$.

a) The admissible uncertainty aversion set $C_{N}$

We may assume that without uncertainty all firms make positive profits, so we get integers $N$ bounded by 1 and $\left[N_{\omega}\right]$, and the set $C_{N}$ introduced in Section 3.1 becomes here: $C_{N}=\{c \in[0,1)$ : $\Pi(0, N)>0\} ; N=2,3, \cdots,\left[N_{\omega}\right]$. The existence of positive fixed costs and the increasing marginal costs assumption imply that the mean cost is U-shaped. It means that for each $N$, there must be an uncertainty aversion level $c(N)$ such that $\Pi(c(N), N)=0$. So, $c(N)$ is the maximum aversion level supporting nonnegative profits in the industry.

By analysing the profit function $\Pi(c, N)$ under the current assumptions, Boff (1998) shows that $c(N)$ is a continuous decreasing function of $N$ as long as the Cournotian quantities $q(c, N)$ are smaller than the collusive equilibrium quantities, say $\widehat{q}(N)$ for a cartel with size $N$. In this paper we take this result for granted. So, the set $C_{N}$ 
here assumes the form: $C_{N}=[0, c(N))$ for $N=2,3, \cdots\left[N_{\omega}\right] \cdot{ }^{17}$

b) Comparative statics

In the symmetric case, the expression for $a_{j}(c)$ given with proposition 1 becomes

$$
a(c, N)=\frac{(N-1) \phi^{\prime \prime}\left(q P^{\prime \prime}+P^{\prime}\right) \sigma}{(1-c)(N+1)\left(\frac{Q}{N+1} P^{\prime \prime}+P^{\prime}\right)-\phi^{\prime \prime}}
$$

The substitution of this value in (3.3) gives:

$$
\sigma(c, N)=\frac{q P^{\prime}+P}{(1-c)(N+1)\left(\frac{Q}{N+1} P^{\prime \prime}+P^{\prime}\right)-\phi^{\prime \prime}}
$$

Now the substitution of $\sigma(c, N)$ above in $\chi(c, N)$ given in note (iii) of Section 3.2, leads to:

$$
\sigma(c, N)=\chi(c, N)
$$

Equations (4.0) and (4.1) allow to make explicit the following corollary:

Corollary 2: Under identical firms and identical uncertainty aversion coefficients assumptions, whenever the MDMR condition holds, (i) a marginal increase in the uncertainty aversion coefficient for any producer reduces the aggregate output; (ii) the marginal effect of the uncertainty aversion on the aggregate industry output equals the full effect of the uncertainty aversion on the individual quantities of firms.

\section{Proof: Appendix.}

${ }^{17}$ Notice that if fixed costs are sunken allowing to have $\Pi\left(0, N_{\omega}\right)<0$ we obtain two points annullating profits, say $c_{1}(N), c_{2}(N)$. Here we deal with the greater value of them.

Revista de Econometria 18 (2) Novembro 1998 
Notice that the above results are set without the constant returns to scale assumption (as did in corollary 1). By direct derivation of the profit function the symmetric assumptions, it is not hard to show that the full effect on the firms' profit of a symmetric variation in the uncertainty aversion coefficient for all producers will be given by:

$$
\sum_{j=1}^{N} \frac{\partial \Pi(c, N)}{\partial c_{j}}=\left[P+Q P^{\prime}-\phi^{\prime}\right] \sigma(c, N)
$$

The equation $P+Q P^{\prime}-\phi^{\prime}=0$ gives the first order condition for the joint profit maximization without uncertainty (cartel). Then, for an uncertainty coefficient $c \in C_{N}$ verifying the MDMR condition the derivative in (4.2) is positive as long as $P+Q P^{\prime}-\phi^{\prime}<0$ that is to say, as long as the Cournotian quantities $q(c, N)$ are larger than the cartel quantities $\widehat{q}(N)$. The derivative in (4.2) is negative for $P+Q P^{\prime}-\phi^{\prime}>0$, that is whenever $q(c, N)<\widehat{q}(N)$ and it is null for $q(c, N)=\widehat{q}(N)$.

With these results we are now able to establish the following proposition:

Proposition 2: In a symmetric Cournotian market with barriers to entry, if the MDMR condition is verified at any $c \in C_{N}$, for each $N=2,3, \cdots\left[N_{\omega}\right]$ there is an admissible aversion coefficient $\widehat{c}(N)$ equating the Cournotian output with the output of a cartel with size $N: Q(\widehat{c}(N), N)=\widehat{Q}(N)$. Moreover, for $c>\widehat{c}(N) \rightarrow Q(c, N)<$ $\widehat{Q}(N)$.

\section{Proof: Appendix.}

Under the above assumptions point $\widehat{c}(N)$ is unique. According to the result of the corollary 2 , uncertainty aversion leads agents to 
produce lower quantities than they would do under uncertainty neutrality. The collusive effect is obtained because up to the level $\widehat{c}(N)$, their behavior allows them to capturate higher profits by making further cuts in the amount supplied. Proposition 2 formally shows how a collusive outcome can be achieved through competition among selfseeking and uncertainty averse players. It gives a new result: a noncooperative cartel may be endogenously generated in a one-shot game without any formal commitment among the producers whenever they are symmetrically uncertainty averse in a specific way. ${ }^{18}$ When all producers are (relatively) strong uncertainty averse $(c>\widehat{c}(N))$ and maximize independently their own profit function, they would be led to obtain a joint output smaller than what they could obtain under perfect collusion. The result of the proposition guarantees also that the derivative given in (4.2) is cancealed at $c=\widehat{c}(N)$. As a function of $c$ the profit of an individual firm $\Pi(c ; N)$ achieves a maximum at this point (with value identical to the cartel profit). In most cases, $\widehat{c}(N)$ increases with $N$ within $\left(1, N_{\omega}\right) \cdot{ }^{18}$

In order to provide a proper illustration for the present result, if we consider a linear demand with quadratic costs model (from now on referred as $L D-Q C$ model) $P(Q)=\alpha-Q,(\alpha>Q)$ with $\phi(q)=k+q^{2},(k>0)$ for $q>0$ and $\phi(0)=0$ (nonsunken fixed costs) we obtain the critical uncertainty level $\widehat{c}(N)=\frac{N-1}{N+1}$.

\footnotetext{
${ }^{18}$ The game literature we know up to now obtain collusive outcomes from noncooperative settings only for repeated games where the optimal responses of the players are contingent and the strategies are drawn from precommitted actions (like trigger strategies).

${ }^{19}$ The use of the chain rule in the derivation of both sides of the the equation $Q(\widehat{c}(N), N)=\widehat{Q}(N)$ yields: $\frac{\partial \widehat{c}(N)}{\partial N}=-\left[\frac{\partial Q(\widehat{c}, N)}{\partial N}-\frac{\partial \widehat{Q}(N)}{\partial N}\right] / N \sigma(\widehat{c}, N)$. From the Corollary 2(i), the sign of the denominator is negative. Then the derivative $\frac{\partial c(N)}{\partial N}$ is positive (negative) as long as, at the collusive outcome, the elasticity of the Coumotian output with respect to the industry size is greater (smaller) than that for the cartel output.
} 


\subsection{Free-Entry.}

We now cancel the requirement of the exogeneity of $N$ and allow firms to entry into the market. So, the industry size will be endogenously determined and we shall assume now the number of firms $N$ is a real variable (we neglect again the so-called "integer problem"). Then, given the uncertainty aversion parameter $c$ of the producers, consider an industry size such that $N_{\omega}(c) \in \max \{N: \Pi(c, N) \geq 0\}$ and assume further that there is $N_{\omega}(c)$ which causes the profit of firms to vanish i.e., making $\Pi\left(c, N_{\omega}(c)\right)=0$, with $N_{\omega}(c)>1$ (where $\omega$ stands again for the relevant parameters of the model). Of course, $N_{\omega}(0)=N_{\omega}$, as defined in the previous section. We will also assume $N_{\omega}(c)$ is a continuous function on the domain of $c$. We introduce now the following notations for the competitive equilibrium quantities and output $q_{\omega}(c) \equiv q\left(c, N_{\omega}(c)\right), Q_{\omega}(c) \equiv Q\left(c, N_{\omega}(c)\right)$ respectively. Similarly, we note $P_{\omega}, \phi_{\omega}$ for prices, costs and $P_{\omega}^{\prime}, \phi_{\omega}^{\prime}$ for their derivatives, where the subscript $\omega$ indicates that functions are evaluated at $N=N_{\omega}(c)$. Analogously, we write $\sigma_{\omega}(c)$ and $\chi_{\omega}(c)$ for the derivatives obtained along (4.0) and the equality (4.1). Lastly, $\frac{\partial Q_{\omega}(c)}{\partial N}$ and $\frac{\partial q_{\omega}(c)}{\partial N}$ are the derivatives of $Q(c, N)$ and $q(c, N)$ evaluated at $N-N_{\omega}(c)$, e.g. $\frac{\partial Q_{\omega}(c)}{\partial N}=\frac{\partial Q\left(c, N_{\omega}(c)\right)}{\partial \bar{N}}$.

At the competitive industry size, the admissible uncertainty aversion set, say $C_{\omega}$, must be defined as: $C_{\omega}=\left\{c \in[0,1): N_{\omega}(c)\right.$ $>1\}$. Under some conditions that would appear more clearly ahead, $C_{\omega}$ may assume the form of a demi-open interval $\left[0, c_{\omega}\right)$, where $c_{\omega}$ is obtained from the equation $N_{\omega}\left(c_{\omega}\right)=1$.

\section{a) Comparative Statics ${ }^{20}$}

When there is $[N]$ firms participating the Cournot game under uncertainty $\left(\Gamma_{[N]}\right)$ the value of the profit function for a firm

${ }^{20}$ Details of the calculations made in this section are available with the authors upon request. 
whose producer has uncertainty aversion $c$ at the symmetric equilibrium, is given by: $\Pi(c, N)=q(c, N) P(N q(c, N))-\phi(q(c, N))$. Given a common uncertainty aversion $c$, at the competitive equilibrium $q_{\omega}(c)$, firms are maximizing profits. Thus, we take the full differential on both sides of the equation $\Pi(c, N)=$ const. and evaluate the derivatives of this differential at $c_{i}=c_{j}=c$. For obtaining the derivatives in the sequel we adopt the following approximations: $\left.\sum_{1 \leq j \leq\left[N_{\omega}(c)\right]} \frac{\partial q_{i}(c, N)}{\partial c_{j}}\right|_{N=N_{\omega}(c)} ^{c_{j}=c} \simeq \chi_{\omega}(c)$ and $\left[N_{\omega}(c)\right] q_{\omega}(c) \simeq Q_{\omega}(c)$ which are necessary for defining summation over integer indices. Define now $\gamma_{\omega}(c) \equiv \frac{\partial Q_{\omega}(c)}{\partial N} \frac{N_{\omega}(c)}{Q_{\omega}(c)}$ for the elasticity of the competitive output w.r.t. the industry size and the values of the Lerner index and the price-elasticity of the market demand $\lambda_{\omega}(c)$ and $\varepsilon_{\omega}(c)$ (respectively) at the competitive symmetric equilibrium. Therefore, by using the equations (4.0) and identifying $d N_{\omega}(c) / d c$ with the derivative we arrive to:

$$
\left.\frac{\partial N_{\omega}(c)}{\partial c_{j}}\right|_{c_{j}=c}=-\frac{N_{\omega}(c)}{q_{\omega}} \sigma_{\omega}\left[\frac{\lambda_{\omega} \varepsilon_{\omega}-1}{D_{\omega}}\right]
$$

where $D_{\omega}(c) \equiv \gamma_{\omega}\left\{\lambda_{\omega} \varepsilon_{\omega}-1\right\}-\lambda_{\omega} \varepsilon_{\omega}$.

Note now $\left.\sigma^{\omega}(c) \equiv \frac{\partial Q_{\omega}(c)}{\partial c_{j}}\right|_{c_{j}=c}$ for the marginal effect on the competitive equilibrium output of a variation in the uncertainty aversion of any producer. By using the definition $Q_{\omega}(c)=Q\left(c, N_{\omega}(c)\right)$ and the equation (4.0)(at $N=N_{\omega}(c)$ ) along with (4.3), we obtain for this derivative the following expression:

$$
\sigma^{\omega}(c)=-\sigma_{\omega}\left[\frac{\gamma_{\omega}\left(N_{\omega}(c)-1\right)\left\{\lambda_{\omega} \varepsilon_{\omega}-1\right\}+\lambda_{\omega} \varepsilon_{\omega}}{D_{\omega}}\right]
$$

Turning now to the competitive equilibrium quantities of the firms say, $q_{\omega}(c)=q\left(c, N_{\omega}(c)\right)$, we define $\chi^{\omega}(c) \equiv \sum_{1 \leq j \leq\left[N_{\omega}(c)\right]} \frac{\partial q_{i \omega}(c)}{\partial c_{j}}$ for the full effect of a symmetric variation in the uncertainty aversion of all producers on the symmetric equilibrium quantities produced by 
the firms. Then, in order to obtain $\chi^{\omega}(c)$ we use the identity (4.1) again and we take into account the identity $Q_{\omega}(c)=N_{\omega}(c) q_{\omega}(c)$ along with (4.3). By doing so, after some algebric manipulations we arrive to:

$$
\chi^{\omega}(c)=\chi_{\omega}\left[\frac{\left\{\left(1-\gamma_{\omega}\right)\left[N_{\omega}(c)\right]+\gamma_{\omega}\right\}\left\{\lambda_{\omega} \varepsilon_{\omega}-1\right\}-\lambda_{\omega} \varepsilon_{\omega}}{D_{\omega}}\right]
$$

Note now $\widehat{q}(n)$ and $\widehat{Q}(n)=n \widehat{q}(n)$ for the optimal quantities and output (respectively) for a symmetric cartel with $n$ firms. Let $\widehat{n}$ be a maximum cartel size supporting nonnegative profits, that is, $\widehat{n} \in$ $\arg \max \{n: \widehat{\Pi}(n) \geq 0\}$. Without loss of generality, assume that $\widehat{n}$ is an integer number. The equation $\left(P_{\omega}^{\prime} Q_{\omega}+P_{\omega}-\phi_{\omega}^{\prime}\right)=\frac{P_{\omega}}{\varepsilon_{\omega}}\left[\lambda_{\omega} \varepsilon_{\omega}-1\right]=$ 0 is the first order condition for a joint profit maximization of the symmetric cartel with size $n=\left[N_{\omega}(c)\right]$. So, as long as $\lambda_{\omega}(c) \varepsilon_{\omega}(c)<$ 1 , the competitive Cournotian quantities (and output) are larger than the cartel quantities (and output): $q_{\omega}(c)>\widehat{q}\left(N_{\omega}(c)\right.$ ) (and $Q_{\omega}(c)>$ $\left.\widehat{Q}\left(N_{\omega}(c)\right)\right)$. Whenever $\lambda_{\omega}(c) \varepsilon_{\omega}(c)>1$, Cournotian quantities (and output) are smaller than the cartel quantities (and output) and when $\lambda_{\omega}(c) \varepsilon_{\omega}(c)=1$ they are identical.

b) Effects of the uncertainty aversion on production

For examining the collusive effects of the uncertainty aversion on the optimal production choices under the free-entry regime one should be aware that, for some uncertainty aversion level $c$, the Cournotian quantities and output for an industry with size $\left[N_{\omega}(c)\right]$ could only be identical with the quantities and the output of a cartel with the same size if $\left[N_{\omega}(c)\right]=\widehat{n}$. This is so because of the zero profit condition. In the sequell we prove a proposition ensuring that the functional equation $\left[N_{\omega}(c)\right]=\widehat{n}$ has (at least) one solution under the MDMR condition.

Proposition 3: Under the symmetric and free entry assumptions, if the MDMR condition is verified for all $c \in C_{\omega}$, then there is 
some symmetric uncertainty aversion level $\widehat{c}_{\omega}\left(\widehat{c}_{\omega} \in C_{\omega}\right)$ equating the competitive Cournotian quantities and output with the quantities and the output of a cartel with size $\widehat{n}$ that is, $q_{\omega}\left(\widehat{c}_{\omega}\right)=\widehat{q}(\widehat{n})$ and $Q_{\omega}\left(\widehat{c}_{\omega}\right)=\widehat{Q}(\widehat{n})$

\section{Proof: See Appendix.}

Of course, at $c=\widehat{c}_{\omega}$ we have $\left[N_{\omega}\left(\widehat{c}_{\omega}\right)\right]=\widehat{n}$ and the following sequence of equalities hold: $\sigma^{\omega}\left(\widehat{c}_{\omega}\right)=\chi^{\omega}\left(\widehat{c}_{\omega}\right)=\chi_{\omega}\left(\widehat{c}_{\omega}\right)=\sigma_{\omega}\left(\widehat{c}_{\omega}\right)$. As we mentionned above, the point $\hat{c}_{\omega}$ need not be unique. Proposition 3 is the free-entry counterpart of the proposition 2, giving the collusive effect of the uncertainty when the industry size $N$ is exogenous. The coefficient $\widehat{c}_{\boldsymbol{\omega}}$ is a structural parameter. Its magnitude signals how unlikely it is for the competitive industry to achieve a cooperative outcome in a self-enforcing way, that is, without any formal agreement among the producers. In the $L D-Q C$ model, the value of $\widehat{c}_{\omega}\left(\widehat{c}_{\omega}=1-8 / \omega ; \omega=\alpha^{2} / k>8\right)$ is increasing in the market size $\alpha$ and decreasing in the fixed cost $k$. We obtain also $N_{\omega}(c)=\frac{2}{1-c}\left[\sqrt{\frac{1}{2}} \omega(1-c)-1\right]=1$ and $\widehat{n}=\frac{1}{4} \omega-1$.

Now we are going to examine how the functionals $Q_{\omega}(c)$ and $q_{\omega}(c)$ behave locally for small variations in the (symmetric) uncertainty aversion parameters of the producers. For this aim we use the derivatives $\sigma^{\omega}(c)$ and $\chi^{\omega}(c)$ given in (4.4) and (4.5) respectively. In order to make the analysis easy, we will assume that the collusive uncertainty aversion level $\widehat{c}_{\omega}$ obtained in the proposition 3 is unique. Under this hipothesis, the term $\lambda_{\omega}(c) \varepsilon_{\omega}(c)-1$ annulates only once (at $c=\widehat{c}_{\omega}$ ). Since for $c=0$ the competitive Cournotian quantities (and output) are larger than those corresponding to the cartel with size $N_{\omega}$, we must have $\lambda_{\omega}(0) \varepsilon_{\omega}(0)<1$. So, for $c<\widehat{c}_{\omega}$ we get $\lambda_{\omega}(c) \varepsilon_{\omega}(c)<1$ and the competitive Cournotian quantities (and output) are larger than the cartel quantities (and output): 
$q_{\omega}(c)>\widehat{q}\left(N_{\omega}(c)\right)$ (and $\left.Q_{\omega}(c)>\widehat{Q}\left(N_{\omega}(c)\right)\right)$. For $c>\widehat{c}_{\omega}$ we get $\lambda_{\omega}(c) \varepsilon_{\omega}(c)>1$ and the Cournotian quantities (and output) are smaller than the cartel quantities (and output). Define now the following functional: $E_{\omega}(c) \equiv\left[\frac{1}{\lambda_{\omega}(c) \varepsilon_{\omega}(c)}-1\right]^{-1}$.

Thus, for $c<\widehat{c}_{\omega}, E_{\omega}(c)>0$ and the denominator of the equations (4.3)-(4-5) say, $D_{\omega}(c) \equiv \gamma_{\omega}(c)\left[\lambda_{\omega}(c) \varepsilon_{\omega}(c)-1\right]-\lambda_{\omega}(c) \varepsilon_{\omega}(c)$ is negative. For $c>\widehat{c}_{\omega},-E_{\omega}(c)>0$ and $D_{\omega}(c)$ is negative (positive) according to $\gamma_{\omega}(c)<(>)-E_{\omega}(c)$. Assume further that the MDMR condition holds on $C_{\omega}$, and recall that when the uncertainty aversion of the producers is $c$, at the symmetric equilibrium the market share of any firm is given by $r_{\omega}(c)=\frac{1}{N_{\omega}(c)}$.

Then, looking at (4.4) we find out that $o^{\omega}(c)$ is positive (negative) according to $\gamma_{\omega}(c)>(<) \frac{r_{\omega}(c)}{1-r_{\omega}(c)} E_{\omega}(c)$ whenever $c<\hat{c}_{\omega}$ and $\sigma^{\omega}(c)$ is positive (negative) acording to $\gamma_{\omega}(c)>(<)-E_{\omega}(c)$ whenever $c>\widehat{c}_{\omega}$. Of course, since $\sigma^{\omega}\left(\widehat{c}_{\omega}\right)<0$ there is an uncertainty aversion level $\underline{c} \in \arg \inf _{c \in C_{\omega}} Q_{\omega}(c)$ such that $\widehat{c}_{\omega}<\underline{c} \leq c_{\omega}$. Notice that the effect of uncertainty aversion on the competitive Cournotian output is ambiguous, ${ }^{21}$ particularly when the optimal quantities produced by the firms are larger than those produced optimally under perfect collusion $\left(c<\widehat{c}_{\omega}\right)$. When $c<\widehat{c}_{\omega}$, the condition for the positivity (negativity) of $o^{\omega}(c)$ is favored with a low (high) market share for the firms that is, with an unconcentrated (concentrated) structure for the industry. Also, a price-inelastic market demand (low $\varepsilon_{\omega}(c)$ ) helps the positivity. The sign of $\sigma^{\omega}(c)$ may also depend on the market size. When $c<\widehat{c}_{\omega}$, the condition for the positivity (negativity) of $\sigma^{\omega}(c)$ is favored with a low (high) market share for the firms that is, with an unconcentrated (concentrated) structure for the industry.

\footnotetext{
${ }^{21}$ In a model with symmetric firms where (risk averse) producers face a stochastic market demand Appelbaum \& Katz (1986) found a negative relationship between the competitive industry output and the price-uncertaintyparameter of the (indirect) demand. However, the result is independent of the measure of risk. Neverthless, their paper suggests a lower output under risk aversion than under risk neutrality.
} 
Also, a price-inelastic market demand (low $\varepsilon_{\omega}(c)$ ) helps the positivity. The sign of $\sigma^{\omega}(c)$ may also depend on the market size. The bounding values calculated from the functionals $\gamma_{\omega}(c)$ and $E_{\omega}(c)$ in the $L D-Q C$ model when $c<\widehat{c}_{\omega}$, show a positive $\sigma^{\cdot \omega}(c)$ for $\omega>14.23$ (at $c=0$ ) or for $\omega>23.04$ at $c=1 / 2\left(\sigma^{\omega}(c)\right.$ is negative otherwise for those values of $c$ ). So, when all producers are weakely or moderately uncertainy averse, an increase in the uncertainty aversion parameter of any one of them may increase (reduce) the competitive output of the industry if the market size is relatively large (small) with respect to the fixed costs. As it will appear clearly afterwards, an higher competitive output (w.r.t. certainty) means that the aggregate quantities of the newly entering firms more than offset the aggregate amount of the quantities cut off by the incumbent firms. The following figures depict these features.

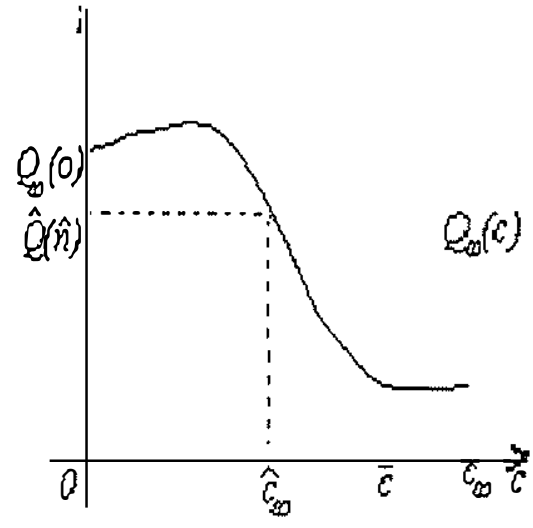

Fig.1(a): Large market size

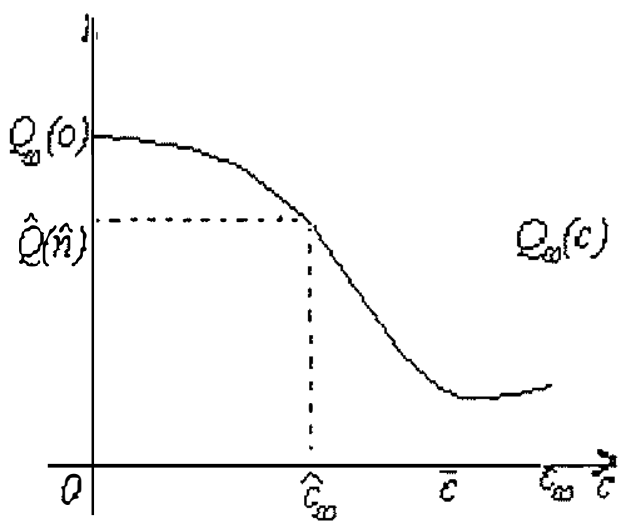

Fig.1(b): Small market size

Figure 1: Competitive output $Q_{\omega}(c)$ under symmetric uncertainty aversion (presumed shape under the MDMR condition) 
These features suggest an important issue for this paper: ${ }^{22}$ if there is free entry into an industry, where all the Cournotian producers are weakely or moderately uncertainty averse and supply for a relatively large market (w.r.t. to the fixed costs), then the equilibrium price achieved under uncertainty $\left(P_{\omega}=\phi_{\omega} / q_{\omega}\right.$ mean cost) should presumably be lower than that which is achieved if all the producers were uncertainty neutral $(c=0)$. By looking now at the equation (4.5), we find out that $\chi^{\omega}(c)$ is positive (negative) acording to $\gamma_{\omega}>(<) \frac{1}{1-r_{\omega}}\left[1+r_{\omega} E_{\omega}\right]$ whenever $c<\widehat{c}_{\omega}$. For $c>\widehat{c}_{\omega}, \chi^{\omega}(c)$ is positive if

$$
\gamma_{\omega}(c)<\min \left\{-E_{\omega}(c) ; \frac{1}{1-r_{\omega}(c)}\left[1+r_{\omega}(c) E_{\omega}(c)\right]\right\}
$$

or if

$$
\gamma_{\omega}(c)>\max \left\{-E_{\omega}(c) ; \frac{1}{1-r_{\omega}(c)}\left[1+r_{\omega}(c) E_{\omega}(c)\right]\right\}
$$

$\chi^{\omega}(c)$ is negative otherwise (the case $\gamma_{\omega}(c)=-E_{\omega}(c)$ being excluded). Of course, since $\chi^{\omega}\left(\widehat{c}_{\omega}\right)<0$ there is uncertainty aversion level $\tilde{c} \in \arg \inf _{c \in C_{\omega}} q_{\omega}(c)$ such that $\widehat{c}_{\omega}<\tilde{c} \leq c_{\omega}$. Here, for $c<\widehat{c}_{\omega}$ the condition for the negativity of $\chi^{\omega}(c)$ is relatively easy. ${ }^{23}$ For the values obtained in the LD-QC model, whenever the producers are not too strong uncertainty averse (whenever $c<\tilde{c}$ ), a symmetric increase in the uncertainty parameter for all of them will likely reduce the optimal quantities produced by each firm.

\footnotetext{
${ }^{22}$ We are not aware of any other equivalent result to the present ours available in the literature.

${ }^{23}$ No unambiguous eff ect of the "price-uncertainty" on the firms' quantities is obtained in Appelbaum \& Katz's paper. It leads them to conclude that at the equilibrium under uncertainty ( (isk), firms could operate either with "excess capacity" or with "undercapacity". The present model shows that under Knightian uncertainty aversion, only undercapacity tipically occurs.
} 
The following picture depicts in a stylized way the optimal behavior of the firm:

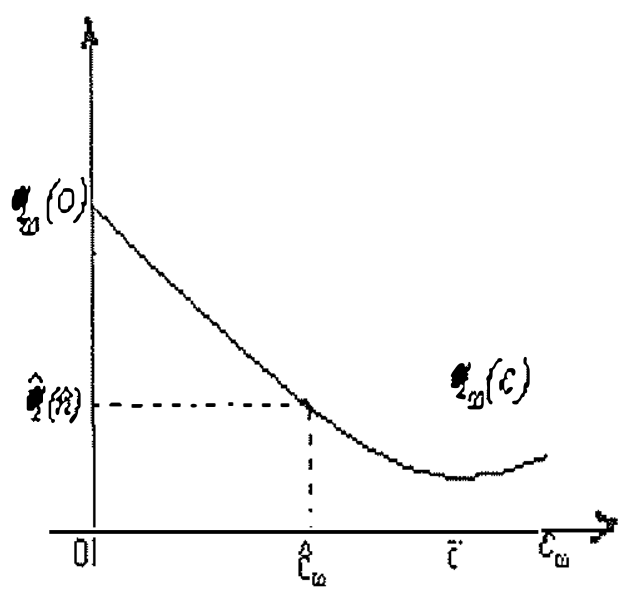

Figure 2: Firms' quantities $q_{\omega}(c)$ under symmetric uncertainty aversion (presumed shape under the MDMR condition)

c) Uncertainty and the market structure

The analysis made in the previous section shows that the symmetry property of the marginal effect and the full effect of uncertainty aversion variations on the output and the firm's quantities that have been obtained before (Section 4.1) does not hold under free-entry. Indeed equations (4.4)-(4.5) embody this divergence, since $\sigma^{\omega}(c) \neq \chi^{\omega}(c)$. In order to explain this, let us start from the symmetric competitive equilibrium. If the uncertainty aversion of all identical producers varies symmetrically, the full effect on the industry output is given by $\left[N_{\omega}(c)\right] \sigma^{\omega}(c)$, while $\left[N_{\omega}(c)\right] \chi^{\omega}(c)$ gives this effect on the aggregate quantities of the individual firms. Then, $\mu_{\omega}(c) \equiv\left[N_{\omega}(c)\right]\left\{\sigma^{\omega}(c)-\chi^{\omega}(c)\right\}$ may be interpreted as a structural component of the uncertainty aversion effect on production, which is 
due to the free-entry assumption. By using (4.4)-(4.5), we obtain

$$
\mu_{\omega}=-\sigma_{\omega} \frac{\left[N_{\omega}(c)\right]^{2}}{D_{\omega}}\left\{\lambda_{\omega} \varepsilon_{\omega}-1\right\} \quad \text { or }\left.\quad \mu_{\omega}(c) \approx Q_{\omega}(c) \frac{\partial N_{\omega}(c)}{\partial c_{j}}\right|_{c_{j}=c}
$$

(by using 4.3).

From the equation (4.3) and the assumptions made in the previous section (the MDMR condition and the unicity of $\widehat{c}_{\omega}$ ), as long as $c<\widehat{c}_{\omega}$, the number of firms $N_{\omega}(c)$ is increasing and then $\mu_{\omega}(c)>0$ : by facing a symmetric increase in the uncertainty aversion for all producers $(d c>0)$, the incumbent producers are cutting off their firm's optimal quantities. The reduction in the current output raises the market price. Then, the prospect to collect positive profits makes room for new outsider producers (with higher uncertainty aversion coefficient $=c+d c$ ) to come into the market. This is why we have $\mu_{\omega}(c)>0$. At $c=\widehat{c}_{\omega}$, the size of the industry reaches its maximum value supporting nonnegative profits $(\widehat{n})$ under the technological and the market constraints and then we have $\mu_{\omega}\left(\widehat{c}_{\omega}\right)=0$. Beyond that level, for some neighborhood in the rhs of $\widehat{c}_{\omega}, \mu_{\omega}(c)$ becomes negative. Indeed, a symmetric increase in the uncertainty aversion on this neighborhood $(d c>0)$ induce the incumbent firms to diminish once again their current optimal quantities. However, the resulting increase in the mean costs now overweighs the increase in the mean revenue, so profits decline. Therefore, negative profits induce $\left[N_{\omega}(c)-N_{\omega}(c+d c)\right]$ firms to leave the industry and $\mu_{\omega}(c)<0$.

It is worthwhile to note that for $c<\widehat{c}_{\omega}$, a higher number of firms operating into the market reduces the market power of each of them in such a way that the aggregate (negative) effect on the individual quantities overides the gross marginal effect on the output. The figure drawn below illustrates typical changes in the Cournotian 
market structure caused by the uncertainty aversion of the producers.

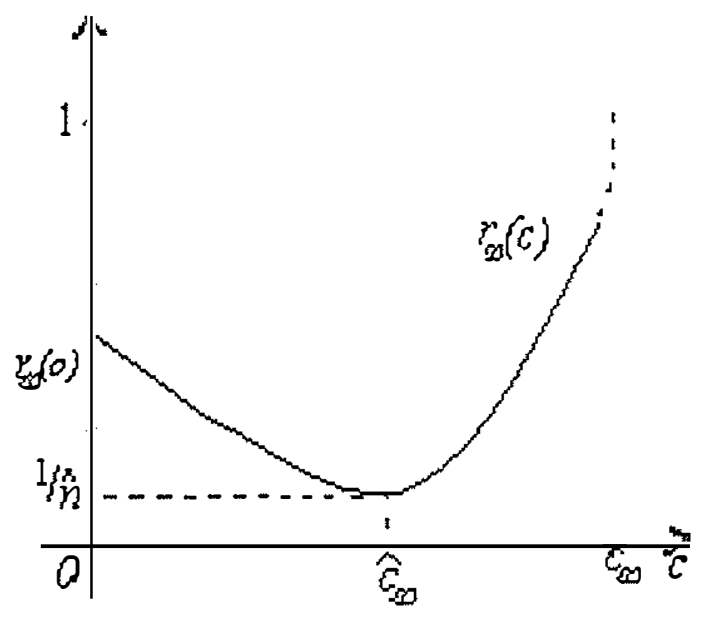

Figure 3: Firms' market shares $r_{\omega}(c)$ under symmetric uncertainty aversion (presumed shape under the MDMR condition)

As the figure above emphasizes, inside an open industry, when the Cournotian producers are all weakely or moderately uncertainty averse $\left(c<\widehat{c}_{\omega}\right)$ competition among them acts in preventing market power for the individual firms. From the point-of-view of market regulatory policies designed to preserve competition among the firms and to protect consumers from overpricing due to market power, these features stress $(i)$ the importance for the regulatory agency to implement actions guaranteeing the proponent firms will meet easy conditions to enter the market; (ii) the current anti-trust laws based on the market share profile of the firms become powerless to protect consumers from the monopoly power if the producers are uncertainty averse. 


\section{Further Issues and Summary of the Results.}

\section{a) Uncertainty aversion asymmetries}

We focus here on a simple Cournotian duopoly game in order to bring out the role of asymmetric behavior of the producers towards uncertainty in providing different industry equilibria with extreme market structures (e.g. $r_{i}=0$ or $r_{i}=1$ ). The corresponding values are calculated for the following linear demand model with constant returns to scale and fixed (nonsunked) costs: $P(Q)=\alpha-\beta Q$; $\phi_{i}\left(q_{i}\right)=k+s_{i} q_{i}$ for $q_{i}>0$ and $\phi_{i}(0)=0 ; k>0, \beta>1 ; Q=q_{1}+q_{2}$; $i=1,2$. For the standard game $\Gamma^{*}:\left(A_{1}, A_{2}, \Pi_{1}^{*}, \Pi_{2}^{*}\right)$ the use of $\Gamma_{i}^{*}$ given in (3.1) and the first order conditions (3.2) for $N=2$ leads to the following optimal solutions:

$$
\begin{aligned}
& q_{i}\left(c_{j}, c_{i}\right)=\frac{1}{3 \beta}\left[\alpha-\left(\frac{2 s_{i}}{1-c_{i}}-\frac{s_{j}}{1-c_{j}}\right)\right] \\
& Q\left(c_{j}, c_{i}\right)=\frac{1}{3 \beta}\left[2 \alpha-\left(\frac{s_{i}}{1-c_{i}}+\frac{s_{j}}{1-c_{j}}\right)\right] .
\end{aligned}
$$

The profit functions are given by $\mathrm{II}_{i}=q_{i}\left[\alpha-\beta Q-s_{i}\right]-k ; i=1,2$. Make now the parametrization $x_{i} \equiv 1-c_{i} ; i=1,2$. It is not hard to verfy that the condition $\mathrm{II}_{i}\left(x_{i}, x_{j}\right) \geq 0$ requires that the polynomial $\varphi_{i}\left(x_{i}\right)=a_{i} x_{i}^{2}+b_{i} x_{i}+d_{i}$ must be nonpositive, where all coefficients are function of $x_{j}$ as follows $a_{i}=-\left[\alpha\left(\alpha-3 s_{i}\right)-9, \beta k\right] x_{j}-\left(2 \alpha-3 s_{i}\right) s_{j}$; $b_{i}=s_{i}\left[s_{j}+\left(7 \alpha-6 s_{i}\right) x_{j}\right] ; d_{i}=2 s_{i}^{2} x_{j}$.

Notice that $\varphi_{i}(0)=2 s_{i}^{2} x_{j} \geq 0 ; \varphi_{i}(1)=\left[9, \beta k-\alpha^{2}+10 \alpha s_{i}-\right.$ $\left.4 s_{i}^{2}\right] x_{j}-2 s_{j}\left(\alpha-2 s_{i}\right)$. The existence of admissible solutions for $\varphi_{i}\left(x_{i}\right)=0$ is assured if $\varphi_{i}(1)<0$. It is not difficult to check that this condition imposes the following upper bound for fixed costs: $k \leq \frac{\alpha\left[\alpha=10 s_{i}\right]+4 s_{i}^{2}+2 s_{j}\left(\alpha-2 s_{i}\right)}{9 \beta} ; i, j=1,2$.

This condition also ensures $a_{1}, a_{2}<0$. The solutions of $\varphi_{i}\left(x_{i}\right)=$ $0,(i, j=1,2)$ are: $x_{i}^{\circ}\left(x_{j}\right)=-\frac{b_{i}}{2 a_{i}}\left[1+\sqrt{1-\frac{4 a_{i} d_{i}}{b_{i}^{2}}}\right] ; i, j=1,2$. 
The maps for the Nash equilibrium under uncertainty (NEU) of the game $\Gamma:\left(A_{1}, A_{2}, \Pi_{1}, \Pi_{2}\right)$ will be depicted by the condition $\mathrm{II}_{i}\left(c_{1}, c_{2}\right) \geq 0$ that is, by the regions $x_{i} \geq x_{i}^{\circ}\left(x_{j}\right), i, j=1,2$. Define then $C^{i}\left(x_{j}\right)=\left\{x_{i} \in[0,1]: x_{i} \geq x_{i}^{\circ}\left(x_{j}\right)\right\} ; i, j=1,2$.

According to the model developed in Section 3.1, the admissible uncertainty aversion set will be here:

$$
C_{2}=\left\{\left(x_{1}, x_{2}\right) \in[0,1]^{2}: \Pi_{1}\left(x_{1}, x_{2}\right) \geq 0 ; \Pi_{2}\left(x_{2}, x_{1}\right) \geq 0\right\} .
$$

Let $\widehat{Q}$ be the joint profit maximization output. For the present model we obtain: $\widehat{Q}=\frac{2 \alpha-\left(s_{1}+s_{2}\right)}{4 \beta}$. The points $\left(x_{1}, x_{2}\right)$ satisfying $Q\left(x_{1}, x_{2}\right) \leq \widehat{Q}$ are those satisfying the inequality: $x_{i} \leq$ $\frac{s_{i}}{(1 / 4)(2 \alpha+3 s)-\left(s_{j} / x_{j}\right)} \equiv f\left(x_{j}\right) ; i, j=1,2$, where $s=s_{1}+s_{2}$.

The following figure 4 depicts in the plan $\left(x_{j}, x_{i}\right) 5$ regions according to which different Cournot-Nash equilibria under uncertainty will emerge for presumably shapes of the curves $x_{i}^{\circ}\left(x_{j}\right)$. U : $\mathrm{II}_{j}$, $\mathrm{II}_{i} \geq 0$ with $Q\left(x_{1}, x_{2}\right)>\widehat{Q} ; \mathrm{U}_{c}: \mathrm{II}_{j}, \mathrm{II}_{i} \geq 0$ with $0<Q\left(x_{1}, x_{2}\right) \leq \widehat{Q}$; $\mathrm{U}_{i}: \mathrm{II}_{j}<0, \mathrm{II}_{i}>0$ : monopoly of firm $i \mathrm{U}_{j}: \mathrm{II}_{j}>0, \mathrm{II}_{i}<0$ : monopoly of firm $j$; $\mathrm{U}_{0}: \mathrm{II}_{j}<0, \mathrm{II}_{i}<0$ with $Q\left(x_{1}, x_{2}\right)=0$ (inactivity).

Here, the admissible uncertainty aversion set is $C_{2}=U \cup U_{c}$. A corresponding set for collusive outcomes is: $U_{i} \cup U_{j} \cup U_{0} \cup U_{c}$. Notice that the points $x_{j}^{*}$ depicted in the figure 4 are obtained solving equations $x_{i}^{\circ}\left(x_{j}^{*}\right)=f\left(x_{j}^{*}\right)$, where $f\left(x_{j}\right)$ is defined above as the bounding function for the collusive levels of the uncertainty aversion $(i, j=1,2) .{ }^{24}$ Therefore, Dow \& Werlang theorem (Section 2) ensures the existence of an $U$-type NEU for every coordinated point

\footnotetext{
${ }^{24}$ In order to calculate points $x_{j}^{*}$, curves $x_{i}^{\circ}\left(x_{j}\right)$ were approximated by $-\theta\left(b_{i} / a_{i}\right)$ where $\theta>1$ was treated as a constant.
}

Revista de Econometria 18 (2) Novembro 1998 
$\left(c_{j}, c_{i}\right) \in[0,1]^{2}$ corresponding to the region $U$ where this point is located. The market share for the firm $i, r_{i}\left(c_{j}, c_{i}\right)=\frac{q_{i}\left(c_{j}, c_{i}\right)}{Q\left(c_{j}, c_{i}\right)}$ can be easily calculated from the above expressions. For instance, an explicit calculation reveals $r_{i}\left(c_{j}, c_{i}\right)$ is greater (lower) than $\frac{1}{2}$ according to $c_{j}>(<) 1-\frac{s_{j}}{s_{i}}\left(1-c_{i}\right)$. Figure 4 shows $r_{i}\left(c_{j}, c_{i}\right)=1$ in the region $U_{i}$ and $r_{i}\left(c_{j}, c_{i}\right)=0$ in the region $U_{j}$. Thus, asymmetric attitudes of producers facing competitive uncertainty affect directly the market structure of the industry. The result obtained agree with those obtained in Section 4.3c for the open industry case. Indeed, when $s_{j}=s_{i}$ the segment of the line $x_{i}=x_{j}$ intersecting the region $U_{c}$ on figure 4 (not depicted) shows that a market price higher than the cartel price can be supported by infinitely many equalitarian market structures.

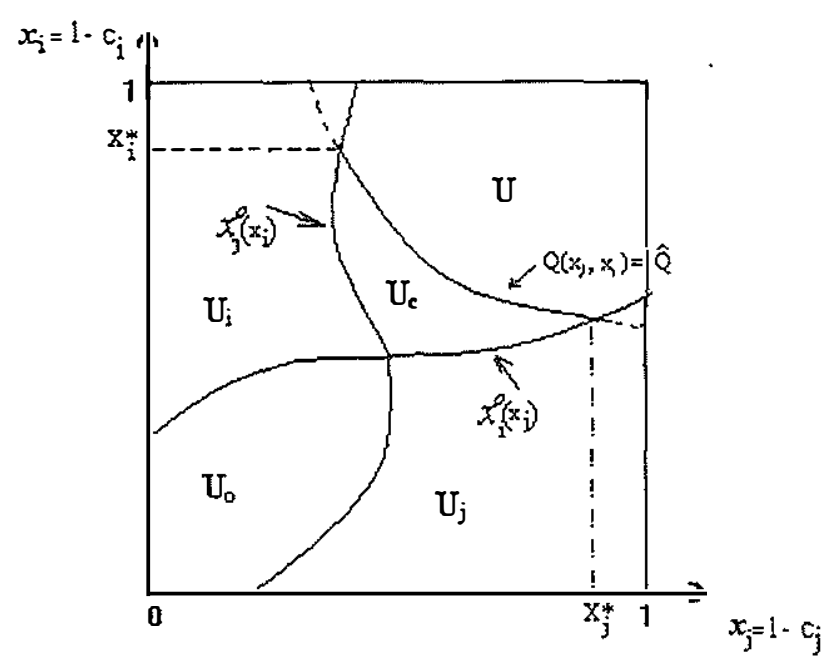

Figure 4: Nash Equilibria under Uncertainty (NEU) of a Cournot duopoly with asymmetric uncertainty aversion parameters for the producers 
b) Extensions

The collusive effects of the uncertainty aversion of the producers in the symmetric case may be further analysed by focusing the profit function and the strategic behavior of firms when the producers are strongly uncertainty averse. Using the first order conditions (3.2) for the symmetric case, in connection with (4.2) (and its counterpart for the free-entry regime), Boff (1998) shows that the producers are implicitly dealing with conjectural variations endogenously fulfilled. The same paper analyses also the welfare aspects of the present model. In Boff (1999) horizontal mergers in Cournotian competitive industries under uncertainty are focused. Important results on the profitability of collusions and the welfare effects of such mergers that are usually obtained under the assumptions that they generate productive synergies or that the game is repeated, are otherwise reproduced in the paper, whenever mergers cause shifts in the uncertainty coefficients of the producers in the expected way. Of course, the present analysis may be extended in many directions (differentiated oligopolies, Bertrand competition, etc). For instance, cases where producers are uncertain about the reaction of competitors to their price moves (as in the kinked demand model) or about costs born by them could motivate research for similar treatments. Of course, the present decision model could be used to solve all decision making problem embedded in a Knightian uncertainty environment which is modelled as a one-shot game. In order to extend its application in game theory an important challenge is to set a theorem for sequential games analogous to the Dow \& Werlang theorem. Such an issue, for instance, could allow one to examine the conditions on the uncertainty parameters ensuring the sub-game perfection property for the Stacklberg equilibrium. ${ }^{25}$

\footnotetext{
${ }^{25}$ The subgame perfection property under uncertainty may be obtained in some specific sequential games (Werlang, 1997).
} 
c) Summary of the Results

i) Independently of the degree of openess of the industry, Cournotian competition among uncertainty averse producers in homogeneous industries typically reduce the optimal amount produced by the individual firms. Moderate or strong aversion parameters generate equilibrium points with large economies of scale for the firms;

ii) In closed industries, the uncertainty aversion always causes to raise the market price. In open industries (under "perfect" entry, i.e. under instantaneuos adjustments of the quantities and the industry size), the aggregate production of the new entrant firms may more than compensate the amount cut off by the incumbent firms if the producers are sufficiently weak averse. It should cause the market price to fall. Such a socially desirable effect could be easily met if the market is large (e.g. price-elastic demand, high reservation price) or fix costs are low;

iii) Whenever producers are not strongly uncertainty averse and there is free-entry, uncertainty aversion acts as preventing monopoly power for the individual firms;

iv) From a game theoretical point-of-view, the collusive effects of the uncertainty aversion obtained along proposition 2 (for closed industries) and proposition 3 (for open industries) show how a cooperative outcome may be endogenously generated in a oneshot game played by self-seeking and uncertainty averse players.

Submitted on March, 1998 and revised on June, 1999.

\section{References}

Appelbaum, E. \& E. Katz. 1986. "Measures of risk aversion: a comparative statics of industry equilibrium". The American Economic Review, 76(3):524-529. 
Hugo Pedro Boff and Sergio Ribeiro da Costa Werlang

Boff, H.P. 1998. "Conjectural Variations under Knightian Uncertainty". mimeo.

. 1999. "Collusion and Horizontal Mergers under Knightian Uncertainty". mimeo.

Dow, J. \& S.R.C. Werlang. 1992a. "Uncertainty aversion, risk aversion, and the optimal choice of Portfolio". Econometrica 60(1), 197-204.

- 1992b. "Excess volatility of stock prices and knightian uncertainty". European Economic Review 36, 631-638.

- 1994. "Nash equilibrium under knightian uncertainty: breaking down backward induction". Journal of Economic Theory $64,305-324$.

Eichberger, J. \& D. Kelsey. 1996. "Uncertainty aversion and preference for randomisation". Journal of Economic Theory 71, 31-43.

Fershtman, C. \& K.L. Judd. 1987. "Equilibrium incentives in oligopoly". The American Economic Review 77(5), 927-940.

Gilboa, I. 1987. "Expected utility theory with purely subjective nonadditive probabilities". Journal of Mathematical Economics 16, $65-88$.

Gilboa, I. \& D. Schmeidler. 1989. "Maximin expected utility with non-unique prior". Journal of Mathematical Economics 18, 141153.

Grossman, S. 1981. "An introduction to the theory of rational expectations under asymmetric information". Review of Economic Studies, XLVIII, 541-559.

Knight, F. 1921. "Risk, Uncertainty and Profit". Houghton Mifflin, Boston.

Mass-Colell, A.; M.D. Whinston \& J.R. Green. 1995. Microeconomic Theory. Oxford University Press. 
Radner, R. 1989. "Uncertainty and general equilibrium". In Eatwell, J; Milgate, M. \& Newman, P. (ed.), General Equilibrium. W.W. Norton, 305-323.

Sklivas, S.D. 1987. "The strategic choice of managerial incentives". Rand Journal of Economics, 18(3), 452-458.

Sarin, R. \& P. Wakker. 1992. "A simple axiomatization of nonadditive expected utility". Econometrica 60(6), 1255-1272.

Schmeidler, D. 1989. "Subjective probability and expected utility without additivity". Econometrica, 57(3).

Simonsen, M.H. \& S.R.C. Werlang. 1991. "Subadditive probabilities and portfolio inertia". Revista de Econometria, XV(1), Rio de Janeiro, 1-19.

Sonnenschein, H. \& J. Roberts. 1977. "On the foundations of the theory of monopolistic competition". Econometrica, 45(1), 101113.

Werlang, S.R.C. 1997. "A Notion of Subgame Perfect Nash Equilibrium under Knightian Uncertainty". mimeo.

\section{Appendix.}

Proof of Proposition 1: By taking the derivatives on both sides of the first order condition for the $\mathrm{i}^{\text {th }}$ firm (3.2) w.r.t. $c_{i}$ and $c_{j}(i \neq j)$ we obtain, respectively:

$$
\begin{aligned}
& \left\{\left(1-c_{i}\right) P^{\prime}-\phi_{i}^{\prime \prime \prime}\right\} \frac{\partial q_{i}}{\partial c_{i}}+\left(1-c_{i}\right)\left[q_{i} P^{\prime \prime}+P^{\prime}\right] \sigma_{i}=\left[q_{i} P^{\prime \prime}+P^{\prime}\right]( \\
& \left\{\left(1-c_{i}\right) P^{\prime}-\phi_{i}^{\prime \prime \prime}\right\} \frac{\partial q_{i}}{\partial c_{j}}+\left(1-c_{i}\right)\left[q_{i} P^{\prime \prime}+P^{\prime}\right] \sigma_{j}=0
\end{aligned}
$$


where $\sigma_{i} \equiv \partial Q / \partial c_{i}$. Summing-up both sides of (A2) for $i(i \neq j)$ gives:

$$
\left[Q_{(j)} P^{\prime \prime}+(N-1) P^{\prime}\right] o_{j}+\left[\sigma_{j}-\frac{\partial q_{j}}{\partial c_{j}}\right] P^{\prime}=\sum_{\substack{i=1 \\ i \neq j}}^{N} \frac{1}{1-c_{i}} \phi_{i}^{\prime \prime} \frac{\partial q_{i}}{\partial c_{j}} .
$$

Note $a_{j}$ for the term in the rhs of this equation. After arranjing terms in the lhs, we arrive to:

$$
\left[Q_{(j)} P^{\prime \prime}+N P^{\prime}\right] \sigma_{j}-\frac{\partial q_{j}}{\partial c_{j}} P^{\prime}=a_{j}
$$

By putting $i=j$ in (A1) we solve for $\partial q_{j} / \partial c_{j}$ and subtitute this derivative in the latter equation. The solution in $\sigma_{j}$ gives:

$$
o_{j}=\frac{a_{j}\left[\left(1-c_{j}\right) P^{\prime}-\phi_{j}^{\prime \prime}\right]+P^{\prime \prime}\left[q_{j} P^{\prime}+P\right]}{P^{\prime \prime}\left[\left(1-c_{j}\right) Q P^{\prime}-Q_{(j)} \phi_{j}^{\prime \prime}\right]+P^{\prime}\left[\left(1-c_{j}\right)(N+1) P^{\prime}-N \phi_{j}^{\prime \prime}\right]}
$$

which is equation (3.3). The equations (3.4)-(3.5) are obtained subtituting back in (A1) and (A2) the values of $\sigma_{i}$ and $\sigma_{j}$ obtained from (3.3). Notice that without further assumptions, the derivatives in (3.3)-(3.5) only can be solved implicitly.

Proof of Corollary 1: As we assume positive marginal revenue $\left(q_{i} P^{\prime}+P>0\right)$, the above sign relations are obtained in a straightforward manner by taking into account of (3.6) and by setting $\phi_{i}^{\prime \prime}=\phi_{j}^{\prime \prime}=0$ in the equations (3.3)-(3.5).

Proof of Corollary 2: The result (i) is trivially obtained from equation (4.0): the marginal revenue is positive and, if the MDMR 
conditions holds, $\sigma(c, N)<0$. The result (ii) comes from the identity (4.1), which is obtained by simple substitution (as indicated above).

Proof of Proposition 2: With identical firms, the cartel output $\widehat{Q}(N)$ is smaller than the Cournotian output without uncertainty: $\widehat{Q}(N)<Q(0, N)$ at each $N$. Besides, at $c=c(N)$ profits must be decreasing since we have assumed at $q(0, N)$ all firms make nonnegative profits; thus from equation (4.2) we must have $q(c(N), N)<\widehat{q}(N)$. From the corollary $2(\mathrm{i}), Q(c, N)$ is a decreasing function of $c$. Therefore, given $N$ the continuity property of $Q(\cdot, N)$ ensures it intersects $\widehat{Q}(N)$ at some uncertainty aversion level $\widehat{c}(N) \in(0, c(N))$.

Proof Proposition 3: The following inequalities hold: $\inf _{c \in C_{\omega}} Q_{\omega}(c)<\widehat{Q}(\widehat{n}) \leq Q_{\omega}(0)$. Indeed, the rhs inequality is trivial: on the zero isoprofit curve, the Cournotian output without uncertainty $(c=0)$ is never lower than the cartel output. For the lhs one, assume that the point $\widehat{c}_{\omega}$ exists $\left(\widehat{c}_{\omega} \in C_{\omega}\right)$. Then, $\lambda_{\omega}\left(\widehat{c}_{\omega}\right) \varepsilon_{\omega}\left(\widehat{c}_{\omega}\right)=1$ and from (4.4), $\sigma^{\omega}\left(\widehat{c}_{\omega}\right)=\sigma_{\omega}\left(\widehat{c}_{\omega}\right)$ which is negative under the MDMR condition. This implies the lhs inequality. Now, under the current assumptions, $Q_{\omega}(c)=Q\left(c, N_{\omega}(c)\right)$ is a continuous functional on $C_{\omega}$. Hence, the above inequalities and the continuity property of $Q_{\omega}(c)$ together ensure the funcional intercepts $\widehat{Q}(\widehat{n})$ at some uncertainty level $\widehat{c}_{\omega} \in C_{\omega}$. 